\title{
Tricalbin proteins regulate plasma membrane phospholipid homeostasis
}

\author{
Ffion B. Thomas ${ }^{1}$, Deike J. Omnus ${ }^{1,2}$, Jakob M. Bader ${ }^{1,3}$, Gary H. C. Chung ${ }^{1}$, \\ Nozomu Kono ${ }^{4}$ and Christopher J. Stefan ${ }^{1}$
}

\begin{abstract}
${ }^{1}$ MRC Laboratory for Molecular Cell Biology, University College London, Gower Street, London WC1E 6BT
\end{abstract}

${ }^{2}$ Present address: Science for Life Laboratory, Department of Molecular Biosciences, The Wenner-Gren Institute, Stockholm University, Stockholm, Sweden.

${ }^{3}$ Present address: Department of Proteomics and Signal Transduction, Max Planck Institute of Biochemistry, Martinsried, Germany.

${ }^{4}$ Department of Health Chemistry, Graduate School of Pharmaceutical Sciences, The University of Tokyo, Bunkyo-ku, Tokyo 113-0033, Japan.

Correspondence: Christopher J.Stefan, c.stefan@ucl.ac.uk

Running Title: Tricalbins regulate phospholipid homeostasis

Keywords: endoplasmic reticulum-plasma membrane contacts, extendedsynaptotagmin proteins, phosphoinositide metabolism, phospholipid homeostasis, plasma membrane integrity, tricalbin proteins 


\section{Abstract}

The evolutionarily conserved extended synaptotagmin (E-Syt) proteins are calciumactivated lipid transfer proteins that function at contacts between the endoplasmic reticulum and plasma membrane (ER-PM contacts). However, roles of the E-Syt family members in PM lipid organisation remain unclear. Among the E-Syt family, the yeast tricalbin (Tcb) proteins are essential for PM integrity upon heat stress, but it is not known how they contribute to PM maintenance. Using quantitative lipidomics and microscopy, we find that the Tcb proteins regulate phosphatidylserine homeostasis at the PM. Moreover, upon heat-induced membrane stress, Tcb3 co-localises with the PM protein Sfk1 that is implicated in PM phospholipid asymmetry and integrity. The Tcb proteins also promote the recruitment of Pkh1, a stress-activated protein kinase required for PM integrity. Phosphatidylserine has evolutionarily conserved roles in PM organisation, integrity, and repair. We suggest that phospholipid regulation is an ancient essential function of E-Syt family members in PM integrity. 


\section{Introduction}

Maintaining the mechano-chemical properties of the plasma membrane (PM) is essential to vital processes including selective ion and nutrient transport, as well as size and shape control in all living cells. Accordingly, the PM has a distinctive lipid composition in eukaryotic cells, including high sterol and sphingolipid content as well as an enrichment of phosphatidylserine (PS) in its cytosolic leaflet that endows the PM with its unique identity, biophysical properties, organisation, and integrity (Schneiter et al., 1999; van Meer et al., 2008; Yeung et al., 2008; Lingwood and Simons, 2010; Bigay and Antonny, 2012; Holthuis and Menon, 2014). PM lipid composition is achieved and maintained, as needed, through the selective delivery of lipids from the endoplasmic reticulum (ER) where they are synthesized to the PM by vesicular and non-vesicular transport pathways. Vesicular lipid trafficking occurs via the secretory pathway alongside PM-bound proteins (Klemm et al., 2009; Fairn et al., 2011). It is also clear that lipid transfer proteins mediate non-vesicular lipid exchange between the ER and PM in the control of PM lipid composition and homeostasis (Kaplan and Simoni, 1985; Urbani and Simoni, 1990; Vance et al., 1991; Holthuis and Menon, 2014; Wong et al., 2019). Membrane contact sites between the ER and the PM, termed ER-PM contacts, are proposed to serve as integral sites for the coordinated regulation of lipid metabolism and transport (Pichler et al., 2001; Chang et al., 2017; Balla et al., 2020; Nishimura and Stefan, 2020). However, a strict requirement for ER-PM contacts in non-vesicular transport of lipids from the ER to PM has been recently questioned (Quon et al., 2018; Wang et al., 2020), necessitating further evaluation of the vital roles of ER-PM contacts, as well as the proteins proposed to form and function at these important cellular structures. 
Whilst roles of several tether and lipid transfer proteins identified at ER-PM contacts are established, functions of the extended synaptotagmin (E-Syt) protein family members are incompletely understood and even controversial. The E-Syt proteins, as well as their budding yeast orthologs, named tricalbins, are anchored in the ER membrane via a N-terminal hairpin (Giordano et al., 2013) and interact with the PM in a phosphoinositide lipid- and $\mathrm{Ca}^{2+}$-dependent manner via their multiple $\mathrm{C}$-terminal cytoplasmic C2 domains (Chang et al., 2013; Giordano et al., 2013; Idevall-Hagren et al., 2015; Saheki et al., 2016; Bian et al., 2018). They also feature a central cytosolic synaptotagmin-like, mitochondrial (SMP) domain that dimerizes and contains a deep hydrophobic groove previously shown to bind and transport lipids in vitro (Schauder et al., 2014; Saheki et al., 2016; Yu et al., 2016; Bian et al., 2018; Bian and De Camilli, 2019; Qian et al., 2021). Whilst cellular roles of E-Syt proteins as ER-PM tethers are well-described (Giordano et al., 2013, Fernández-Busnadiego et al. 2015), precise roles of the E-Syts the control of membrane lipid dynamics in vivo are enigmatic. One study demonstrated a role of the E-Syts in the transfer of diacylglycerol from the PM to the ER during the phosphoinositide cycle, but loss of the E-Syt1/2/3 proteins had no significant effect on phosphoinositide lipid synthesis or the homeostasis of other phospholipids at the PM (Saheki et al., 2016). An earlier study found that depletion of the E-Syt1/2 proteins impaired the re-synthesis of phosphatidylinositol $(4,5)$ bisphosphate, commonly termed $\mathrm{PI}(4,5) \mathrm{P}_{2}$, during the phosphoinositide cycle and suggested a role of E-Syt-mediated ER-PM contacts in the transfer of phosphatidylinositol from the ER to the PM (Chang et al., 2013). Yet another study has even suggested a role for E-Syt2 in $\mathrm{PI}(4,5) \mathrm{P}_{2}$ turnover (Dickson et al., 2016). Whilst the findings in these studies are not necessarily mutually exclusive or contradictory, they highlight unresolved issues regarding the roles of the E-Syts in PM lipid homeostasis. 
The budding yeast E-Syt orthologs, the tricalbins (Tcb1/2/3), have also been shown to play a role in ER-PM contact formation (Manford et al., 2012; Toulmay and Prinz, 2012; Collado et al., 2019; Hoffmann et al., 2019). Two recent studies used advanced cryoelectron tomography to reveal peaks of extreme ER membrane curvature at Tcbmediated ER-PM contacts (Collado et al., 2019; Hoffmann et al., 2019). In particular, one study also found that Tcb-dependent ER-PM contacts are induced upon PM stress conditions and are required to maintain PM integrity upon stress conditions (Collado et al., 2019). Moreover, computational modelling suggested that the regions of extreme ER membrane curvature may facilitate lipid transfer from the ER to the PM at Tcbmediated ER-PM contacts (Collado et al., 2019). However, potential functions of the Tcb proteins in lipid transport at ER-PM contacts remain to be experimentally tested. Consequently, mechanistic insight into the roles of the Tcb proteins in PM lipid homeostasis and integrity is lacking.

In this study, we use quantitative lipidomics and microscopy approaches to elucidate roles of the Tcb proteins in the control of PM lipid composition. The data show that the Tcb proteins regulate phospholipid homeostasis at the PM upon stress conditions. In particular, the results are consistent with a role of ER-PM contacts in the delivery of certain PS and phosphatidylethanolamine (PE) species, but not phosphatidylinositol $(\mathrm{PI})$, from the ER to the PM. Furthermore, we find that Tcb3 co-localises with the PM protein Sfk1, an ortholog of the mammalian TMEM150/FRAG1/DRAM proteins, that is implicated in stress-induced $\mathrm{PI}(4,5) \mathrm{P}_{2}$ synthesis and phospholipid asymmetry at the PM (Audhya and Emr, 2002; Chung et al., 2015; Mioka et al., 2018). Finally, we find that the Tcb proteins promote the recruitment of Pkh1, a stress-activated protein kinase required for PM integrity, to the PM upon stress conditions. Altogether, our findings 
indicate that the Tcb proteins function as inducible ER-PM tethers necessary for PM phospholipid homeostasis upon stress conditions, providing new mechanistic insight into Tcb protein function at ER-PM contact sites.

\section{Results}

\section{The tricalbins regulate phosphoinositide homeostasis at the PM}

Several proteins have been shown to form and function at ER-PM contacts in yeast, including Scs2/22 (VAP orthologs), Ist2 (ANO8/TMEM16 ortholog), Lam1-4 (GRAMD1/Aster orthologs), and the tricalbin (Tcb) proteins (Loewen et al., 2007; Manford et al., 2012; Gatta et al., 2015) (Figure 1A). The aim of this study is to elucidate functions of the Tcb proteins at ER-PM contacts that have remained incompletely understood. Under normal growth conditions, loss of Tcb1, Tcb2, and Tcb3 (in tcb1/2/3 cells) does not result in obvious effects on ER-PM tethering (Manford et al., 2012) or phospholipid homeostasis (Figures 2 and 3). However, roles of the Tcb proteins in ER-PM tethering become apparent upon loss of additional proteins that form ER-PM contacts, including Scs2/22 and Ist2 (Figure 1A) (Manford et al., 2012; Collado et al., 2019). Specifically, Tcb-mediated ER-PM contacts are induced upon loss of the Scs2/22 and Ist2 proteins (in scs2/22 $\Delta$ ist2 $\Delta$ triple mutant cells) (Collado et al., 2019), and loss of Tcb1/2/3 in combination with loss of Scs2/22 and Ist2 results in additive defects in ER-PM tethering (Manford et al., 2012). However, specific roles of the Tcb proteins in PM lipid homeostasis have not been rigorously examined. We therefore monitored the consequential effects of loss of the Tcb proteins in scs2/22 ist2 $\Delta$ triple mutant cells on PM lipid homeostasis.

The E-Syt1 protein has been shown to be specifically activated upon increases cytoplasmic calcium $\left(\mathrm{Ca}^{2+}\right)$ (Fernandez-Busnadiego et al., 2015; Idevall-Hagren et al., 
2015; Bian et al., 2018). To confirm that Tcb-mediated ER-PM contacts are induced in cells lacking Scs2/22 and Ist2 (scs2/22 ist2 $\Delta$ cells) (Collado et al., 2019), we performed control experiments to monitor the cytoplasmic $\mathrm{Ca}^{2+}$ reporter GCaMP3 in scs2/22 $\Delta$ ist2 $\Delta$ cells. Consistent with Tcb activation, GCaMP3 fluorescence was increased in $s c s 2 / 22 \Delta$ ist $2 \Delta$ cells as compared to wild-type cells, as measured by highcontent quantitative flow cytometry assays (2-fold; Figure 1B) and fluorescence microscopy (Figure 1C). Furthermore, impairment of $\mathrm{Ca}^{2+}$ influx in the scs2/22 $\Delta$ ist2 $\Delta$ mutant cells phenocopied loss of the Tcb proteins in this mutant background (scs2/22 $\Delta$ ist2 $\Delta$ tcb1/2/3s cells, also named $\Delta$ tether cells). Specifically, loss of the stretchactivated $\mathrm{Ca}^{2+}$ channel Mid1 (lida et al., 1994) in the scs2/22 (scs2/22 $\Delta$ ist2 $\Delta$ mid1 $\Delta$ ) conferred increased resistance to the drug myriocin, similar to the $\Delta$ tether mutant cells (Figure S1A). Thus, cytoplasmic $\mathrm{Ca}^{2+}$ is elevated in scs2/22 ist2 $\Delta$ cells, consistent with a previous study (Kato et al., 2017), and the Mid1dependent high-affinity $\mathrm{Ca}^{2+}$ influx system (termed HACS) (Muller et al., 2001) may contribute to Tcb protein function.

Following these control experiments, we investigated roles of the Tcb proteins in phosphoinositide metabolism at the PM using quantitative microscopy and mass spectrometry-based lipidomics. $\mathrm{PI}(4,5) \mathrm{P}_{2}$ and its precursor PI4P (phosphatidylinositol 4-phosphate) are the two major phosphoinositide species present at the PM in yeast and are generated through sequential phosphorylation of $\mathrm{PI}$ at the PM (Figure 2A and S2A). As expected, localisation of the PI4P and $\mathrm{PI}(4,5) \mathrm{P}_{2}$ biosensor FLAREs (fluorescent lipid-associated reporters), GFP-P4C and GFP-2xPH $\mathrm{PLC}_{\mathrm{P}}$ respectively, was not significantly affected by loss of the Tcb proteins (tcb1/2/3 $\Delta$ cells), as compared to wild type control cells (Figures 2B, C and D). In contrast, there was a significant

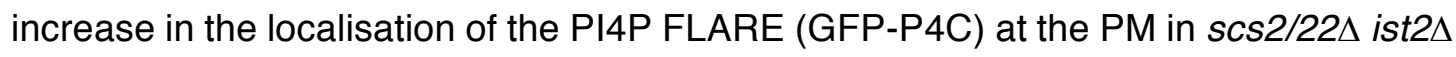


cells, as compared to wild type control cells (Figures 2B and C). Previous studies have shown that Scs2/22 and Ist2 recruit the PI4P exchange proteins Osh2, Osh3, Osh6, and Osh7 to ER-PM contacts (Loewen and Levine, 2005; D'Ambrosio et al., 2020) and loss of Scs2/22 and Ist2 results in increased PI4P levels (Manford et al., 2012). As Tcb-mediated ER-PM contacts are induced in cells lacking Scs2/22 and Ist2 (scs2/22 $\Delta$ ist2 $\Delta$ ), we next monitored distribution of the PI4P and $\mathrm{PI}(4,5) \mathrm{P}_{2}$ FLAREs in scs2/22 $\Delta$ ist2 $\Delta$ cells that also lacked the Tcb proteins ( $\Delta$ tether). Interestingly, whilst there was a significant increase in the PI4P FLARE at the PM of $\Delta$ tether cells compared to scs2/22 $\Delta$ ist2 $\Delta$ cells (Figures $2 \mathbf{B}$ and $\mathbf{C}$ ), there was a decrease in the relative levels of

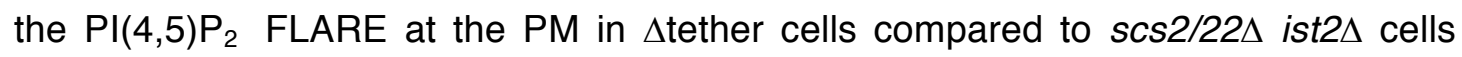
(Figures 2B and D). Thus, the Tcb proteins are not required for PI4P generation at the $\mathrm{PM}$, but they may contribute to $\mathrm{PI}(4,5) \mathrm{P}_{2}$ homeostasis at the $\mathrm{PM}$.

Next, we confirmed the $\mathrm{PI} 4 \mathrm{P}$ and $\mathrm{PI}(4,5) \mathrm{P}_{2}$ FLARE results using quantitative lipidomics. For these experiments, we measured levels of phosphoinositide species in each of the ER-PM tether mutants by liquid chromatography-electrospray ionizationtandem mass spectrometry (LC-ESI-MS/MS) analysis (Clark et al., 2011). Consistent with the microscopy results, levels of mono-unsaturated phosphatidylinositol phosphate (PIP), that constitute the majority of PI4P species generated at the PM (Wenk et al., 2003; Nishimura et al., 2019), progressively increased between wild type control cells, scs2/22 $\Delta$ ist $2 \Delta$ cells, and $\Delta$ tether cells with the $\Delta$ tether cells containing significantly higher PIP steady-state levels than the scs2/22 $\Delta$ ist2 $\Delta$ cells (Figures 2E and S2B). Remarkably, however, the level of mono-unsaturated phosphatidylinositol bis-phosphate $\left(\mathrm{PIP}_{2}\right)$ did not reflect the increase in PIP steady-state levels in the $\Delta$ tether cells (Figures 2F and S2B). In particular, scs2/22 $\Delta$ ist2 $\Delta$ cells displayed increases in both $36: 1 \mathrm{PIP}$ and $36: 1 \mathrm{PIP}_{2}$ steady-state levels compared to wild type 
control cells (5-fold and 2-fold, respectively; Figures 2E and 2F). However, whilst the $\Delta$ tether cells (also lacking the Tcb proteins) displayed a further increase in 36:1 PIP levels (1.5-fold as compared to scs2/22 $\Delta$ ist2 $\Delta$ cells; Figure 2E), 36:1 $\mathrm{PIP}_{2}$ steadystate levels were decreased (1.7-fold as compared to scs2/22 $\Delta$ ist2 $\Delta$ cells; Figure 2F). Likewise, 34:1 PIP levels were increased in the $\Delta$ tether cells as compared to scs2/22 $\Delta$ ist2 $\Delta$ cells (1.8-fold; Figure S2B), whereas $34: 1 \mathrm{PIP}_{2}$ levels were slightly decreased in the $\Delta$ tether cells (Figure S2B). As expected, no significant differences were detected between tcb1/2/3 $\Delta$ cells and wild type control cells (Figure 2 and S2B). Intriguingly, none of the strains tested showed significant changes in steady-state levels of any PI species (Figure S2B). Previous studies have implicated E-Syt family members in recycling diacylglycerol (DAG) from the PM to the ER and in the transfer of PI from the ER to the PM during the phosphoinositide cycle (Chang et al., 2013; Saheki et al., 2016; Nath et al., 2020). However, whilst PI homeostasis and PI4P synthesis at the PM apparently do not require the Tcb proteins, conversion of $\mathrm{PI} P \mathrm{P}$ to $\mathrm{PI}(4,5) \mathrm{P}_{2}$ at the PM is impaired. Altogether, these results point to a function that has yet to be described for metazoan E-Syt family members.

\section{The tricalbins regulate phospholipid homeostasis at the PM}

We next investigated how the Tcb proteins might contribute to $\mathrm{PI}(4,5) \mathrm{P}_{2}$ homeostasis at the PM. PI4P 5-kinase (PIP5K) activity has been shown to be directly regulated by anionic phospholipids, including PS that is enriched in the cytosolic leaflet of the PM and contributes to its overall negative charge (Fairn et al., 2009; Nishimura et al., 2019). PS is synthesized in the ER via the CDP-DAG pathway in yeast and either converted to other phospholipids (Figures $\mathbf{3 A}$ and S3A) or transferred to the PM via vesicular and non-vesicular transport pathways. The generation of Tcb-mediated ER peaks facing the PM has been suggested to facilitate non-vesicular lipid transport from 
the ER to the PM (Collado et al., 2019). We therefore considered whether the Tcb proteins regulate non-vesicular delivery of PS to the PM. First, we analysed the distribution of a PS FLARE (GFP-Lact-C2) in the same series of ER-PM tether mutants by quantitative microscopy. Under normal growth conditions, loss of the Tcb proteins did not significantly affect the localisation of GFP-Lact-C2 at the PM as compared to wild type control cells (Figures 3B and C). However, the relative fluorescence intensity of GFP-Lact-C2 at the PM was significantly reduced in $\Delta$ tether cells as compared to scs2/22 $\Delta$ ist2 $\Delta$ cells (Figures 3B and C). This effect was also observed when comparing the $s c s 2 / 22 \Delta$ ist2 $\Delta$ and $s c s 2 / 22 \Delta$ ist2 $\Delta$ mid $1 \Delta$ mutants (Figure S1B).

We further investigated roles of the Tcb proteins in membrane lipid homeostasis using quantitative lipidomics. Consistent with the microscopy results, steady-state levels of PS were reduced in the $s c s 2 / 22 \Delta$ ist $2 \Delta$ and $\Delta$ tether mutant cells, but not in $t c b 1 / 2 / 3 \Delta$ cells, as compared to wild type control cells (Figures 3D and S3B). Moreover, specieslevel analyses revealed a specific reduction in mono-unsaturated 34:1 PS, which is the major PS species enriched at the PM (Schneiter et al., 1999), in $\Delta$ tether cells compared to $s c s 2 / 22 \Delta$ ist2 $\Delta$ cells ( $>7$-fold; Figures 3D and S3B). In contrast, there were no significant differences in the levels of di-unsaturated 32:2 or 34:2 PS in any of the strains examined (Figure S3B), indicating that PS synthesis per se was not completely disrupted by loss of the ER-PM tether proteins. Consistent with this, cho1 $\Delta$ mutant cells defective in PS synthesis rely upon exogenous ethanolamine or choline in order to support PE and PC synthesis for growth (Atkinson et al., 1980), but the $\Delta$ tether cells are viable in the absence of exogenous ethanolamine and choline and grow on standard media (see Figure S1). Thus, whilst levels of 'ER-like' di-unsaturated PS species are retained, loss of Tcb activity in the scs2/22 $\Delta$ ist2 $\Delta$ cells resulted in a 
decrease in PM-specific mono-unsaturated 34:1 PS species, consistent with impaired transport of newly synthesized mono-unsaturated 34:1 PS from the ER to the PM.

In yeast, PS can be converted to phosphatidylethanolamine (PE) through decarboxylation reactions carried out by Psd1 and Psd2, and PE can be methylated by Cho2 and Opi3 to generate phosphatidylcholine (PC) (Figures 3A and S3A). A previous study found that loss of Psd1 is synthetic lethal in the $\Delta$ tether cells (Wang et al., 2020), suggesting that PS species may be converted to other phospholipids in the $\Delta$ tether cells in order to prevent membrane organelle dysfunction. Accordingly, quantitative lipidomic analyses in this study revealed specific changes in PE and PC species in the mutant cells. First, there were significant decreases in monounsaturated 32:1 and 34:1 PE, the major PE species enriched at the PM (Schneiter et al., 1999), in the scs2/22 $\Delta$ ist2 $\Delta$ and $\Delta$ tether mutant cells as compared to wild type cells (Figures 3E and S3B). Second, mono-unsaturated 34:1 PE levels were further decreased in the $\Delta$ tether cells as compared to scs2/22 $\Delta$ ist2 $\Delta$ cells (4-fold; Figures $3 E$ and S3B), revealing a role of the Tcbs in regulation of 34:1 PE homeostasis. In contrast, there was no significant difference in the levels of di-unsaturated 34:2 PE in any of the strains examined (Figure S3B), indicating that PE synthesis was not blocked in the ER-PM tether mutants. Furthermore, there was a significant increase in di-unsaturated forms of PC $(32: 2,34: 2$, and 36:2 PC) in the scs2/22 $\Delta$ ist2 $\Delta$ and $\Delta$ tether mutant cells as compared to wild type cells (Figures 3F and S3B). Finally, diunsaturated PC species were further increased in the $\Delta$ tether cells as compared to scs2/22 $\Delta$ ist2 $\Delta$ cells (Figures 3F and S3B). Altogether, the results suggest that the Tcb proteins are needed to sustain delivery of 34:1 PS (and 34:1 PE) to the PM in the absence of Scs2/22 and Ist2. Furthermore, mono-unsaturated PS (and PE) species retained in the ER may be further desaturated and converted to di-unsaturated PC 
species in the mutant cells. Although, the data do not exclude a possible role of the Kennedy pathway in the accumulation of PC species in the scs2/22 $\Delta$ ist2 $\Delta$ and $\Delta$ tether mutants.

Tricalbins are required for PM phospholipid homeostasis and PM integrity under heat shock conditions

Sfk1 is an integral PM protein that has been implicated in PM phospholipid asymmetry and PM integrity (Mioka et al., 2018), as well as heat-induced $\mathrm{PI}(4,5) \mathrm{P}_{2}$ synthesis (Audhya and Emr, 2002). Likewise, mammalian Sfk1 orthologs, the TMEM150 proteins, have been implicated in $\mathrm{PI}(4,5) \mathrm{P}_{2}$ re-synthesis following phospholipase $\mathrm{C}$ activation (Chung et al., 2015). We observed that the ER-localised Tcb3 protein is in close proximity to the integral PM protein Sfk1, as assessed by bimolecular fluorescence complementation (BiFC) split GFP assays (Figures 4A and B). In control experiments, Tcb3 split GFP fusion proteins formed cortical patches dependent on the Tcb3 C2 domains (Figure S4A) that target Tcb3 to the cortical ER (Manford et al., 2012). In addition, Sfk1 and Tcb3 did not associate with the ER membrane protein Sec61 in BiFC split GFP assays (Figure S4A), indicating a specific association between Sfk1 and Tcb3. Consistent with this, the C-terminal cytoplasmic domain of Sfk1 was required for efficient association with Tcb3, as the BiFC split GFP signal intensity significantly decreased in cells expressing a truncated version of Sfk1 $\left(\mathrm{Sfk} 1^{\Delta 286-353}\right)$ (Figure 4B). As mentioned, Sfk1 has been implicated in PM lipid organisation and integrity (Mioka et al., 2018), as well as heat-induced $\mathrm{PI}(4,5) \mathrm{P}_{2}$ synthesis at the PM (Audhya and Emr, 2002). Tcb3 has been shown to be necessary for the formation of heat-induced ER-PM contacts and for the maintenance of PM integrity upon heat stress conditions (Collado et al., 2019). We therefore assessed the localisation of Tcb3-GFP with Sfk1-mCherry following a brief heat shock 
(10 $\left.\min 42^{\circ} \mathrm{C}\right)$. Sfk1 and Tcb3 displayed increased co-localisation at the cell cortex upon a brief incubation at $42^{\circ} \mathrm{C}$ (Figures $4 \mathrm{C}$ and $\left.\mathrm{D}\right)$. In control experiments, a shift to $42^{\circ} \mathrm{C}$ induced heterogeneous transient cytoplasmic $\mathrm{Ca}^{2+}$ bursts up to 15 -fold higher than basal levels at $26^{\circ} \mathrm{C}$, as detected by GCaMP3 fluorescence (Figures S4A, B, and C). Altogether, these results indicated that Tcb3 is localised in proximity to Sfk1 at the PM, especially in response to heat stress conditions that elevate cytoplasmic $\mathrm{Ca}^{2+}$ signalling and induce Tcb3-mediated ER-PM tethering.

We next addressed whether the Tcb proteins regulate PS at the PM in response to heat stress. Remarkably, whilst wild type cells showed only a small drop in relative levels of the PS FLARE at the PM after a brief shift from $26^{\circ} \mathrm{C}$ to $42^{\circ} \mathrm{C}, \mathrm{PM}$ localisation of the PS FLARE significantly decreased in the $t c b 1 / 2 / 3 \Delta$ mutant cells at $42^{\circ} \mathrm{C}$ (Figures 5A and B). A previous study has implicated E-Syt1 in recycling DAG from the PM to the ER during the phosphophoinositide cycle (Saheki et al., 2016). However, in control experiments, the DAG FLARE GFP-C1 $1_{\mathrm{PKD}}$ was not stabilised at the PM in $t c b 1 / 2 / 3 \Delta$ mutant cells at $26^{\circ} \mathrm{C}$ or $42^{\circ} \mathrm{C}$ as compared to wild type control cells (Figure S5A). Thus, the Tcb proteins are required for phospholipid, but not glycerolipid, homeostasis at the PM upon heat stress. Regardless, these results do not exclude roles for the Tcb proteins in DAG transport at other inter-organelle contacts or under other stress conditions.

As discussed, the Tcb proteins form heat-induced ER-PM contacts and are required for PM integrity under these conditions (Collado et al., 2019). Yet, how the Tcb proteins contribute to PM integrity is not known. A previous study reported that Pkh1, an ortholog of mammalian phosphoinositide-dependent protein kinase-1 (PDK1), assembles at cortical patches in response to a brief shift to $42^{\circ} \mathrm{C}$ and is required for 
PM integrity (Omnus et al., 2016). Pkh1, along with its paralog Pkh2, activates the protein kinases Ypk1 and Ypk2 (AGC kinase family members) that have essential roles in cell signalling, endocytosis, lipid metabolism, and PM integrity (Casamayor et al., 1999; Sun et al., 2000; Friant et al., 2001; Roelants et al., 2002; Roelants et al., 2011; Muir et al., 2014; Omnus et al., 2016). We examined Pkh1 localisation in wild type and tcb1/2/3 $\Delta$ cells using a functional GFP-Pkh1 fusion under non-stress and heat stress conditions $\left(26^{\circ} \mathrm{C}\right.$ and $\left.42^{\circ} \mathrm{C}\right)$. Consistent with a previous study (Omnus et al., 2016), GFP-Pkh1 was diffusely localised in the cytoplasm of wild type cells at $26^{\circ} \mathrm{C}$. However, upon a brief heat shock ( $10 \mathrm{~min} 42^{\circ} \mathrm{C}$ ), increased numbers of cortical puncta were observed along with some intracellular puncta (Figures $5 \mathrm{C}$ and $\mathbf{D}$ ). The number of cortical GFP-Pkh1 foci per cell after heat shock was significantly lower in tcb1/2/3A mutant cells (>2-fold; Figures 5 C and D). Surprisingly, a previous study found that $\Delta$ tether cells displayed constitutive recruitment of Pkh1 even under normal growth conditions (Omnus et al., 2016). However, this apparent discrepancy may be attributed to increased levels of PI4P in the PM of the $\Delta$ tether cells but not $t c b 1 / 2 / 3 \Delta$ cells (see Figure 2) that may be detected by the PH-like domain of Pkh1 (Figure S5B) (Fidler et al., 2016). The precise lipid-binding specificity of the Pkh1 PH-like domain will require further examination in future studies. However, consistent with a role of phospholipids in Pkh1 regulation, heat-induced Pkh1 puncta formation was significantly impaired in cells lacking Sfk1 (Figure S5C). As discussed, Sfk1 has been previously implicated in the control of lipid flip and/or flop in the PM bilayer (Mioka et al., 2018). Accordingly,

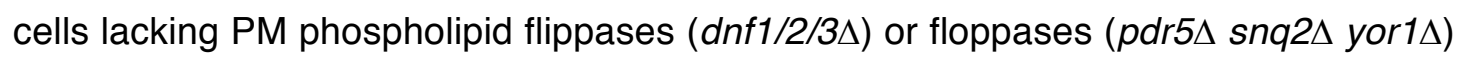
displayed opposite effects on GFP-Pkh1 cortical assemblies at $42^{\circ} \mathrm{C}$ (significantly decreased and increased, respectively; Figure S5D). 
Next, we compared the relative roles of the ER-PM tethering proteins in PM homeostasis upon heat-induced membrane stress. Notably, PM levels of the PS FLARE in $t c b 1 / 2 / 3 \Delta$ cells at $42^{\circ} \mathrm{C}$ resembled those of the $\Delta$ tether cells at $26^{\circ} \mathrm{C}$ and $42^{\circ} \mathrm{C}$ (Figure 6A). In other words, loss of Scs2/22 and Ist2 was not additive with loss of $\operatorname{Tcb} 1 / 2 / 3$ at $42^{\circ} \mathrm{C}$. This finding further suggested that Tcb proteins serve a primary role in PS homeostasis at the PM upon heat stress conditions, while Scs2/22 and Ist2 function under non-stress conditions (Figure 3). A previous study found that Tcb3 was required for the formation of heat-induced ER-PM contacts (Collado et al., 2019). We therefore examined roles of the Tcb3 protein and its domains in PM phospholipid homeostasis and integrity upon heat-induced membrane stress. Loss of Tcb3 alone resulted in a measurable decrease in PM levels of the PS FLARE, as compared to wild type cells at $42^{\circ} \mathrm{C}$ (1.5-fold; Figure $\left.6 \mathrm{~B}\right)$. This was rescued by expression of a Tcb3GFP fusion from a plasmid, but not by a mutant form of Tcb3 lacking the SMP domain (Tcb3 $\triangle$ SMP-GFP) (Figure 6B) or an artificial tether (GFP-MSP-Sac1) (Figure 6B) previously shown to restore ER-PM contacts in the $\Delta$ tether cells (Manford et al., 2012). Accordingly, loss of Tcb3 alone resulted in significant PM integrity defects at $42^{\circ} \mathrm{C}$, as measured by an established quantitative assay ( $>10$-fold increase in propidiumstained $t c b 3 \Delta$ cells; Figure 6C), consistent with a previous study (Collado et al., 2019). This was efficiently rescued by expression of Tcb3-GFP, but not by mutant forms of Tcb3 lacking either the SMP or C2 domains (Tcb3 $\Delta$ SMP-GFP or Tcb3 $\Delta$ C2-GFP, respectively) (Figure 6C) or by the artificial tether (GFP-MSP-Sac1) (Figure 6C). Finally, cells lacking the Tcb proteins displayed significant increases in the amplitude and duration of cytoplasmic $\mathrm{Ca}^{2+}$ bursts at $42^{\circ} \mathrm{C}$, as compared to wild type cells (Figures S6A, B, and C). Altogether, our findings indicate that the Tcb proteins are $\mathrm{Ca}^{2+}$-activated lipid transfer proteins that maintain PM integrity and modulate cytoplasmic $\mathrm{Ca}^{2+}$ signalling upon stress conditions. 


\section{Discussion}

The primary functions of the evolutionarily conserved Tcb/E-Syt family members have remained elusive. This has been partly due to the lack of severe phenotypes observed upon loss of the E-Syt proteins. For example, previous studies reported no obvious defects in triple E-Syt1/2/3 knockout mice (Sclip et al., 2016; Tremblay and Moss, 2016). However, the E-Syt/Tcb proteins have been conserved across species throughout evolution (Lee and Hong, 2006; Kopec et al., 2010; Wong and Levine, 2017), suggesting they must serve important functions that have been overlooked. Indeed, studies in yeast have revealed roles for the Tcb proteins in PM integrity under membrane stress conditions (Aguilar et al., 2007; Omnus et al., 2016; Collado et al., 2019) (see Figures 6 and 7). Likewise, Esyt2/Esyt3 double knockout mouse embryonic fibroblasts displayed decreased migration and survival under in vitro stress culture conditions (Herdman et al., 2014). Furthermore, E-Syt family members have been implicated in neuronal growth and survival (Kikuma et al., 2017; Gallo et al., 2020; Nath et al., 2020). However, mechanistic detail on E-Syt function in these essential processes has been lacking. Using quantitative sensors and lipidomics, we have found that the Tcb proteins control phospholipid homeostasis at the PM. Phospholipid regulation may be an anciently conserved role of the E-Syt protein family in maintaining cellular homeostasis.

Our results indicate that the $\mathrm{Tcb}$ proteins control levels of phospholipids that are enriched at the PM. In particular, localisation of a PS-specific reporter was reduced at the PM upon loss of the Tcb proteins (Figures 3B, 3C, 5A, 5B, 6A, and 6B). PS has essential roles in PM organisation in eukaryotic cells (Yeung et al., 2008; Fairn et al., 2011; Cho et al., 2016; Haupt and Minc, 2017; Sartorel et al., 2018). It is intriguing that previous studies had not uncovered clear roles for the E-Syt proteins in PS regulation. 
However, one study found that whilst mice lacking all three E-Syt were viable, the PS transfer proteins ORP5 and ORP8 were upregulated (Tremblay and Moss, 2016), providing a potential compensatory mechanism. Another study found no differences in PS levels in isolated PM fractions between E-Syt1/2/3 triple knockout and control cells by lipidomics (Saheki et al., 2016); however, this experiment was performed at basal cytoplasmic $\mathrm{Ca}^{2+}$ concentrations where E-Syt activity is low. More recently, the E-Syt proteins have been implicated in $\mathrm{Ca}^{2+}$-mediated PS externalisation (Bian et al., 2018), and this could be attributed to impaired PS delivery to the PM. Yet, potential roles of the E-Syt proteins in PS regulation in mammalian cell remain to be explored.

Our quantitative lipidomics results provide direct evidence that the Tcb proteins control phospholipid homeostasis at the PM. Previous studies have reported alterations in phospholipid levels in $\Delta$ tether yeast cells lacking several ER-PM tether proteins (Quon et al., 2018; Nishimura et al., 2019; Jorgensen et al., 2020; Wang et al., 2020). However, none of these studies addressed the specific contribution of the Tcb proteins. Two studies even questioned the roles of ER-PM contacts in lipid transfer (Quon et al., 2018; Wang et al., 2020). However, neither of these studies analysed acyl chain composition that provides important information on lipid localisation (e.g. ER versus PM species). Our species-level lipidomic results show that mono-unsaturated PS and PE, most notably 32:1 and 34:1 isoforms shown to be enriched at the PM (Schneiter et al., 1999), are specifically depleted upon loss of the Tcb proteins (Figures 3D, 3E, and S3B). However, there was no decrease in di-unsaturated forms of PS and PE (Figure S3B). The specific loss of PM phospholipid species is consistent with a role of the Tcb proteins in coordinating phospholipid synthesis and transfer at ER-PM contacts. All E-Syt family members feature a SMP domain that dimerises and transports glycerolipids in vitro (Lee and Hong, 2006; Toulmay and Prinz, 2012; 
Schauder et al., 2014; Saheki et al., 2016; Yu et al., 2016; Bian et al., 2018; Bian and De Camilli, 2019; Qian et al., 2021). In particular, a recent study demonstrated the ability of the Tcb3 SMP domain to transport phospholipids in vitro (Qian et al., 2021), consistent with our in vivo experiments. Furthermore, the SMP domain is required for Tcb protein localisation and PM integrity (Toulmay and Prinz, 2012; Collado et al., 2019) (Figure 6C), suggesting that the SMP domain-containing Tcb proteins may directly deliver mono-unsaturated phospholipids to the PM at ER-PM contacts (Figure 7). Although, the data do not exclude the possibility that Tcb proteins may serve as tethers for additional lipid transfer proteins at ER-PM contacts.

E-Syt family members have been implicated in distinct steps of the phosphoinositide cycle in metazoan cells. For example, E-Syt proteins have been suggested to facilitate the activity of certain phosphatidylinositol transfer proteins (PITPS) at ER-PM contacts, including Nir2/3 and $\operatorname{Rgd} \beta$ in mammalian cells and Drosophila respectively (Chang et al., 2013; Nath et al., 2020). The Nir2/3 and Rgd $\beta$ PITPs are proposed to transfer PI from the ER to the PM for the generation of PI4P and $\mathrm{PI}(4,5) \mathrm{P}_{2}$ at the PM. However, PI4P synthesis at the PM is not impaired upon loss of the Tcb proteins or other ERPM tethers, Scs2/22 and Ist2 (Figures 2B, 2C, 2E and S2B) (Manford et al., 2012). Thus, the Tcb proteins and other ER-PM contact proteins (Scs2/22 and Ist2) are not required for delivery of $\mathrm{PI}$ to the $\mathrm{PM}$ in yeast. Furthermore, orthologs of the Nir2/Rgd $\beta$ PITPs do not exist in fungi (Hsuan and Cockcroft, 2001), and so putative roles of ESyt proteins in PI transfer may have evolved separately in animals. Mammalian cells lacking the E-Syt proteins also feature prolonged accumulation of DAG at the PM following phospholipase C (PLC)-mediated $\mathrm{PI}(4,5) \mathrm{P}_{2}$ hydrolysis (Saheki et al., 2016), suggesting a defect in recycling DAG to the ER during the phosphoinositide cycle. However, we did not observe accumulation of DAG at the PM in cells lacking the Tcb 
proteins, using a bona fide sensor of Plc1-generated DAG (Figure S5A). This result does not rule out a potential role for the Tcbs, or other SMP domain-containing proteins, in DAG channelling at intra-organelle contacts in yeast. However, given the apparent lack of effects on PI and DAG and the major changes in PS and PE, the Tcb proteins may primarily regulate PS and PE homeostasis at the PM.

While the Tcb proteins and ER-PM contacts are not required for PI transfer, our study does reveal links to PI kinase activity at the PM. In particular, ER-localised Tcb3 is found in proximity to the PM-localised Sfk1 protein (Figure 4). Sfk1 (TMEM150 ortholog) is purportedly a subunit of a PI 4-kinase (PI4K) complex that generates PI4P at the $\mathrm{PM}$ and is required for heat-stimulated $\mathrm{PI}(4,5) \mathrm{P}_{2}$ synthesis (Audhya and Emr, 2002). Moreover, Tcb3 and Sfk1 co-localisation increases following heat shock (Figure 4B). Steady-state lipidomics measurements reveal that while PI4P is elevated upon loss of the Tcb proteins, $\mathrm{PI}(4,5) \mathrm{P}_{2}$ levels are not (Figure 2B, 2D, 2F and $\mathbf{S 2 B}$ ), suggesting that the Tcbs may contribute to the conversion of $\mathrm{PI} 4 \mathrm{P}$ to $\mathrm{PI}(4,5) \mathrm{P}_{2}$. PIP 5kinase is recruited and activated by PS (Fairn et al., 2009; Nishimura et al., 2019), and regulation of PS by the Tcb proteins may be involved. Interestingly, Sfk1 is also implicated in PM phospholipid asymmetry and PM integrity (Mioka et al., 2018). As $\mathrm{PI}(4,5) \mathrm{P}_{2}$ synthesis is required for PM integrity (Audhya et al., 2000; Omnus et al., 2016), one possibility is that Tcb3 and Sfk1 promote the formation of PS-enriched domains that stimulate PIP5K activity upon PM stress. In support of this, the Tcb proteins are required for PS homeostasis at the PM upon heat shock (Figures 5A, 5B, 6A, and 6B). Accordingly, the Tcb proteins are activated upon heat-induced $\mathrm{Ca}^{2+}$ signalling and form distinct ER-PM contacts that are required for PM integrity under these conditions (Figures S4 and 6C) (Omnus et al., 2016; Collado et al., 2019). 
We also show that the Tcb proteins facilitate heat-induced PM recruitment of the protein kinase Pkh1, a PDK1 ortholog necessary for PM integrity upon heat shock (Figures 5C and D) (Roelants et al., 2002; Roelants et al., 2011; Omnus et al., 2016). Both $\mathrm{PI} 4 \mathrm{P}$ and $\mathrm{PI}(4,5) \mathrm{P}_{2}$ are implicated in activation of $\mathrm{Pkh} 1$ at the $\mathrm{PM}$ upon stress conditions (Omnus et al., 2016). The carboxy-terminal region of Pkh1 contains a PH domain-like fold (Fidler et al., 2016) and PH domains often serve as co-incidence detectors of phosphoinositides and PS (Vonkova et al., 2015; Nishimura et al., 2019). Accordingly, mammalian PDK1 is regulated by both $\mathrm{PI}(3,4,5) \mathrm{P}_{3}$ and $\mathrm{PS}$ (Lucas and Cho, 2011; Heras-Martínez et al., 2019). Here, we find that $t c b 1 / 2 / 3 \Delta$ cells have reduced levels of a PS FLARE at the PM after heat shock (Figures 5A and B). Correct maintenance of phospholipids within the PM may be essential for Pkh1 PM recruitment. Consistent with this, loss of PM lipid flippases and floppases modulated Phk1 cortical assembly upon heat shock (Figure S5). Accordingly, Tcb-mediated PS regulation may be critical for Pkh1 localisation and PM integrity. However, our results do not rule out roles of other lipids in PM maintenance and integrity. For example, the Tcb proteins have recently been implicated in non-vesicular transport of ceramide from the ER to Golgi compartments (Ikeda et al., 2020).

Correct maintenance of PS within the PM is integral to cell survival (Matsuo et al., 2007) and in mammalian cells, rearrangements in PS distribution within the PM bilayer acts as a trigger for apoptotic cell death (Fadok et al., 1992). PS also accumulates at sites of PM damage (Horn and Jaiswal, 2019) and is involved in the recruitment of $\mathrm{Ca}^{2+}-$ and PS-binding proteins such as annexins, dysferlins, and synaptotagmins during PM repair (Middel et al., 2016; Boye et al., 2017; Horn and Jaiswal, 2018). However, the mechanism for PS enrichment at sites of PM damage is incompletely understood. Regulation of PS dynamics may be an anciently conserved function of E- 
Syt family members in PM integrity and repair. The synaptotagmin proteins have been the subject of intense focus due to their functions in neurotransmitter release at neuronal synapses (Südhof, 2002; Chapman, 2008), although they also act as $\mathrm{Ca}^{2+}$ dependent regulators of exocytic events in both neuronal and non-neuronal exocrine cells, driving SNARE-mediated membrane fusion (Hui et al., 2009; van den Bogaart et al., 2011; Kim et al., 2012). Accordingly, synaptotagmins and dysferlins are proposed to aid in PM repair by triggering vesicle fusion at sites of injury (Detrait et al., 2000; Lek et al., 2013). Synaptotagmin family members are not conserved in fungi, unlike the extended-synaptotagmins (E-Syts) that are expressed ubiquitously throughout the eukaryotic as well as prokaryotic kingdoms (Wong and Levine, 2017). This hints to a more ancient fundamental function of the E-Syt proteins that predates that of the $\mathrm{C} 2$ domain-containing synaptotagmins. Protein kinase $\mathrm{C}$ isoforms that bear a $\mathrm{C} 2$ domain may be a common ancestral effector protein involved in cellular integrity and exocytosis in yeast and mammalian cells (Levin, 2005; Horn and Jaiswal, 2018; Horn and Jaiswal, 2019). Therefore, the E-Syt family may confer a primordial mechanism for PM maintenance that subsequently evolved in higher eukaryotes in the control of regulated exocytosis during PM wound repair and eventually even insulin and neurotransmitter release.

The importance of $\mathrm{Ca}^{2+}$ signalling in membrane stress responses cannot be understated. Any weakening or disruption of the PM leads to influx of the ion into the cytoplasm, resulting in an increase in cytoplasmic $\mathrm{Ca}^{2+}$ concentration up to two orders of magnitude (from $0.1 \mu \mathrm{M}$ to up to $10 \mu \mathrm{M}$ ) (Jaiswal, 2001). Whilst $\mathrm{Ca}^{2+}$ is recognised as a signal for membrane damage response and repair pathways, increases in cytoplasmic $\mathrm{Ca}^{2+}$ above a defined threshold $(>10 \mu \mathrm{M})$ can result in loss of membrane organelle and cellular integrity leading to cell death, as originally described by 
Zimmerman and Hülsmann as "the calcium paradox" (Zimmerman and Hülsmann, 1966). Accordingly, cells have established rapid response systems to damage- and stress-induced $\mathrm{Ca}^{2+}$ influx. Many of the proteins involved in PM repair mechanisms (including exocytosis-mediated vesicle fusion, endocytosis, membrane shedding, and reorganisation of the cytoskeleton in response to $\mathrm{PM}$ stress or injury) are $\mathrm{Ca}^{2+}$-binding proteins that function as $\mathrm{Ca}^{2+}$ sensors (Benink and Bement, 2005; Cheng et al., 2014; Holmes et al., 2015; Horn and Jaiswal, 2018; Koerdt et al., 2019). The E-Syt family members are no exception and function as sensors of large increases in cytoplasmic $\mathrm{Ca}^{2+}(>1 \mu \mathrm{M})$ (Idevall-Hagren et al., 2015). Accordingly, mammalian E-Syt proteins are regulated by the store-operated $\mathrm{Ca}^{2+}$ entry (SOCE) pathway and subsequently inactivate SOCE (Giordano et al., 2013; Idevall-Hagren et al., 2015). We find that the yeast $\mathrm{Tcbs}$ are active under conditions that increase cytoplasmic $\mathrm{Ca}^{2+}$ signals (Figures 1 and S4) and the Tcbs in turn attenuate cytoplasmic $\mathrm{Ca}^{2+}$ signalling (Figure S6). Thus Tcb/E-Syt function at ER-PM contacts responds to and modulates cytoplasmic $\mathrm{Ca}^{2+}$ signals, and this regulatory system is conserved from yeast to humans.

In summary, we propose that the yeast $\mathrm{Tcb}$ proteins serve as $\mathrm{Ca}^{2+}$-activated ER-PM tethers and lipid transfer proteins that maintain PS levels necessary for PM integrity under stress conditions (Figure 7). Tcb-mediated regulation of PS in the cytosolic leaflet of the PM aids in the direct recruitment of protein and lipid kinases required for PM integrity. Essential roles of the mammalian E-Syt proteins in cell and tissue homeostasis may be revealed under conditions of PM stress conditions, and it will be interesting to re-examine the E-Syt proteins in this context. 


\section{Materials and Methods}

\section{Yeast Strains, Plasmids, Media and Growth Assays}

Descriptions of strains and plasmids used in this study used in this study are listed in Supplemental Tables 1 and 2. Gene deletions and epitope tags were introduced into yeast by homologous recombination (Longtine et al., 1998). The pRS vector series have been described previously (Sikorski and Hieter, 1989). Plasmids were sequenced to ensure that no mutations were introduced due to manipulations. Standard techniques and media were used for yeast and bacterial growth. For plating assays in Figure S1, cells were grown to midlog, adjusted to $1 \mathrm{OD} 600 / \mathrm{ml}$, and serial dilutions were plated on agar media either containing or lacking $0.75 \mu \mathrm{M}$ myriocin. Haploid SplitGFP strains listed in Supplemental Table 1 were made using tagging cassettes (Barnard et al., 2008). Diploid strains were then created by mating to obtain various combinations of $\mathrm{N}$ - and $\mathrm{C}$ - terminal GFP fragment-tagged target proteins.

\section{Live Yeast Cell Imaging}

Fluorescence microscopy experiments were performed on mid-log yeast cultures in synthetic media at the indicated temperatures. Live yeast cell imaging data in all Figures were acquired with a 100x CFI Plan Apochromat VC oil-immersion objective lens (1.4 NA), using a PerkinElmer Ultraview Vox spinning disk confocal microscope that consists of a Nikon TiE inverted stand attached to a Yokogawa CSU-X1 spinning disk scan head, a Hamamatsu C9100-13 EMCCD camera, Prior NanoscanZ piezo focus, and a Nikon Perfect Focus System (PFS). All images were collected as square images with $512 \times 512$ pixels. The number of cells observed in experiments are reported in the figures and figure legends. The brightness and contrast of images were linearly adjusted and cropped in Photoshop (Adobe) for presentation. 


\section{Quantitative Image Analysis}

All quantitative image analyses were conducted using ImageJ/Fiji (Schindelin et al., 2012).

To calculate the specific PM to cytosol (PM/Cyto) ratio of specific lipid species in Figures $\mathbf{S 1}, \mathbf{2}, \mathbf{3}, \mathbf{5}$ and $\mathbf{6}$, the relative fluorescence (relative $\mathrm{F}_{\mathrm{PM}}$ ) was quantified as described in (Nishimura et al., 2019). Briefly, individual cells were chosen from single channel images, lines were drawn cross the mother cell and the corresponding fluorescence intensity profiles were plotted. The two highest intensity values, corresponding to signal at the $\mathrm{PM}$, were averaged $\left(\mathrm{F}_{\mathrm{PM}}\right)$. Intensity measurements were also taken from lines drawn through the cytosol $\left(F_{\text {cytosol }}\right)$ and background $\left(F_{\text {background }}\right)$ and $\mathrm{PM}$ relative fluorescence was calculated by using the equation: relative $F_{\mathrm{PM}}=\left(\mathrm{F}_{\mathrm{PM}^{-}}\right.$ $\left.F_{\text {background }}\right) /\left(F_{\text {cytosol }}-F_{\text {background }}\right)$. Peaks in intensity profiles were automatically calculated by an Excel VBA macro.

Split GFP (Barnard et al., 2008) signal intensity in Figures 4 and $\mathbf{S 4}$ was measured using Fiji. To identify GFP-Pkh1 puncta per cell in Figures $\mathbf{5}$ and S5, individual cells were selected and for each cell, points of interest (GFP-Pkh1 foci) were identified using the Find Maxima tool in Fiji applying appropriate noise tolerance settings.

\section{LC-MS/MS analysis of methylated PIPs}

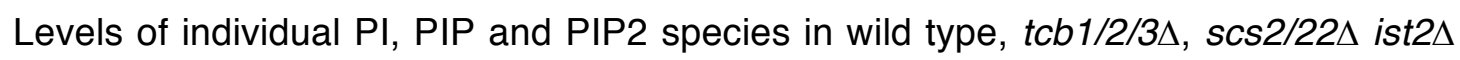
and $\Delta$ tether mutant cell extracts Figures $\mathbf{2}$ and $\mathbf{S 2}$ were analysed as previously described (Nishimura et al., 2019). $20 \mathrm{OD}_{600}$ units of cells were precipitated and washed with cold $4.5 \%$ perchloric acid. For phosphoinositide measurements, cells were resuspended in $500 \mu \mathrm{L} 0.5 \mathrm{M} \mathrm{HCl}$ and disrupted with a $5.0 \mathrm{~mm}$ zirconia bead by 
vigorous shaking (1,500 rpm for $10 \mathrm{~min})$ using Shake Master Neo (BMS, Tokyo, Japan). The homogenates were transferred to new tubes and centrifuged at $15,000 \times$ $g$ for $5 \mathrm{~min}$. The pellets were resuspended in $170 \mu \mathrm{L}$ water and $750 \mu \mathrm{L}$ of $\mathrm{CHCl}_{3} / \mathrm{MeOH} / 1 \mathrm{M} \mathrm{HCl}(2: 1: 0.1, \mathrm{v} / \mathrm{v})$ and incubated for 5 min at room temperature. To each sample $725 \mu \mathrm{l}$ of $\mathrm{CHCl}_{3}$ and $170 \mu \mathrm{l}$ of $2 \mathrm{M} \mathrm{HCl}$ were added, followed by vortexing. After centrifugation at $1,500 \times g$ for $5 \mathrm{~min}$, the lower phase was collected and washed with $780 \mu \mathrm{l}$ of pre-derivatization wash solution (the upper phase of $\mathrm{CHCl}_{3} / \mathrm{MeOH} / 0.01$ $\mathrm{M} \mathrm{HCl}(2: 1: 0.75 \mathrm{v} / \mathrm{v}))$. The lipid extracts were derivatized by adding $50 \mu \mathrm{l}$ of $2 \mathrm{M}$ TMSdiazomethane in hexane. The derivatization was carried out at room temperature for $10 \mathrm{~min}$ and was stopped by adding $6 \mu \mathrm{l}$ of glacial acetic acid. The derivatized samples were washed twice with $700 \mu$ of post-derivatization wash solution (the upper phase of $\mathrm{CHCl}_{3} / \mathrm{MeOH} /$ water $\left.(2: 1: 0.75 \mathrm{v} / \mathrm{v})\right)$. After adding $100 \mu \mathrm{l}$ of $\mathrm{MeOH} / \mathrm{H}_{2} \mathrm{O}(9: 1, \mathrm{v} / \mathrm{v})$, the samples were dried under a stream of $\mathrm{N}_{2}$, dissolved in $80 \mu \mathrm{l}$ of $\mathrm{MeOH}$ and sonicated briefly. After adding $20 \mu \mathrm{l}$ of water, the samples were subjected to LC-ESI-MS/MS analysis. The LC-ESI-MS/MS analysis was performed on a Shimadzu Nexera ultra high performance liquid chromatography system coupled with a QTRAP 4500 hybrid triple quadrupole linear ion trap mass spectrometer. Chromatographic separation was performed on an Acquity UPLC C4 BEH column (100 mm $\times 1 \mathrm{~mm}, 1.7 \mu \mathrm{m}$; Waters) maintained at $40^{\circ} \mathrm{C}$ using mobile phase $A$ (water containing $0.1 \%$ formate) and mobile phase $B$ (acetonitrile containing $0.1 \%$ formate) in a gradient program ( $0-5 \mathrm{~min}: 45 \%$ B; $5-10 \min : 45 \% B \rightarrow 100 \%$ B; $10-15 \min : 100 \%$ B; $15-16 \min : 100 \% B \rightarrow 45 \%$ B; $16-$ 20: $45 \% \mathrm{~B}$ ) with a flow rate of $0.1 \mathrm{~mL} / \mathrm{min}$. The instrument parameters for positive ion mode were as follows: curtain gas, 10 psi; collision gas, 7 arb. unit; ionspray voltage, $4500 \mathrm{~V}$; temperature, $600^{\circ} \mathrm{C}$; ion source gas $1,30 \mathrm{psi}$; ion source gas $2,50 \mathrm{psi}$; declustering potential, $121 \mathrm{~V}$; entrance potential, $10 \mathrm{~V}$; collision energy, $39 \mathrm{~V}$; collision cell exit potential, $10 \mathrm{~V}$. Methylated phosphoinositides and phosphatidylserine were 
identified and quantified by multiple reaction monitoring. For these measurements, internal standards of $10 \mathrm{ng}$ of $17: 0-20: 4 \mathrm{PI}, \mathrm{PI}(4) \mathrm{P}$, and $\mathrm{PI}(4,5) \mathrm{P}_{2}$, and $\mathrm{PS}$ were added to each sample.

\section{Quantitative shotgun lipid MS data acquisition, analysis, and post-processing}

Levels of individual PS, PE and PC species in wild type, tcb1/2/3 $\Delta, \operatorname{scs} 2 / 22 \Delta$ ist2 $\Delta$ and $\Delta$ tether mutant cell extracts in Figures $\mathbf{3}$ and $\mathbf{S 3}$ were determined by mass spectrometry-based quantitative, shotgun lipidomics by Lipotype GmbH (Dresden, Germany) as described (Ejsing et al., 2009; Klose et al., 2012). Total yeast cell lysate samples were diluted to 0.2 OD units using $155 \mathrm{mM}$ ammonium bicarbonate in water to the total volume of $150 \mu$ land were spiked with internal lipid standard mixture. Lipids were extracted using a two-step chloroform/methanol procedure with $750 \mu$ l volume of each organic phase step (chloroform:methanol, $15: 1$ and 2:1 respectively for the $1^{\text {st }}$ and the $2^{\text {nd }}$ step)(Ejsing et al., 2009). After extraction, the organic phase was transferred to an infusion plate and dried in a speed vacuum concentrator. $1^{\text {st }}$ step dry extract was re-suspended in $100 \mu \mathrm{l} 7.5 \mathrm{mM}$ ammonium acetate in chloroform/methanol/propanol $(1: 2: 4, \mathrm{~V}: \mathrm{V}: \mathrm{V})$ and $2^{\text {nd }}$ step dry extract in $100 \mu \mathrm{l} 33 \%$ ethanol solution of methylamine in chloroform/methanol $(0.003: 5: 1 ; \mathrm{V}: \mathrm{V}: \mathrm{V})$. All liquid handling steps were performed using Hamilton Robotics STARlet robotic platform with the Anti Droplet Control feature for organic solvents pipetting. Samples were analysed by direct infusion on a QExactive mass spectrometer (Thermo Scientific) equipped with a TriVersa NanoMate ion source (Advion Biosciences). Samples were analysed in both positive and negative ion modes with a resolution of $R_{m / z=200}=280000$ for $M S$ and $R_{m / z=200}=17500$ for MSMS experiments, in a single acquisition. MSMS was triggered by an inclusion list encompassing corresponding MS mass ranges scanned in $1 \mathrm{Da}$ increments (Surma et al., 2015). Both MS and MSMS data were combined to monitor 
EE, DAG and TAG ions as ammonium adducts; PC as an acetate adduct; and PA, PE, PG, PI and PS as deprotonated anions. Data were analysed with in-house developed lipid identification software based on LipidXplorer (Herzog et al., 2011; Herzog et al., 2012). Data post-processing and normalization were performed using an in-house developed data management system. Only lipid identifications with a signal-to-noise ratio $>5$, and a signal intensity 5 -fold higher than in corresponding blank samples were considered for further data analysis

\section{Quantitative GCaMP3 Fluorescence Assays}

To quantify resting cytosolic $\mathrm{Ca}^{2+}$ levels in Figure 1, strains expressing a cytoplasmic GCaMP3 reporter were grown at $26^{\circ} \mathrm{C}$. For flow cytometry experiments, cells were transferred to PBS. Mean fluorescence of 50,000 events was recorded on a BD Accuri C6 flow cytometer. Background was determined using strains harbouring vector alone. For fluorescence microscopy measurements cells were transferred immediately to a slide and imaged directly. For identification of $\mathrm{Ca}^{2+}$ bursts after heat shock in Figures S4 and S6, cells were incubated for $10 \mathrm{~min}$ at the indicated temperature before being directly transferred to a slide and imaged at max speed for 5 minutes. Individual cells were chosen from single channel time lapse images. Intensity measurements were taken in an area of the same size within the cell $\left(F_{\text {cell }}\right)$ and adjacent background ( $\left.F_{\text {background }}\right)$. The normalised GCaMP3 signal $\left(\Delta F / F_{0}\right)$ was calculated from time lapse images, using the equation: $\Delta \mathrm{F} / \mathrm{F}_{0}=\left(\mathrm{F}_{\text {cell }}\right.$ at time $t-\mathrm{F}_{\text {background }}$ at time $\left.t\right) /\left(\mathrm{F}_{\text {cell }}\right.$ at time $t=0$ - $\mathrm{F}_{\text {background }}$ at time $t=0$ ). Peaks in GCaMP3 fluorescence intensity, representing $\mathrm{Ca}^{2+}$ bursts, were identified using Prism 8 Area under curve function. 


\section{Plasma membrane Integrity Assay}

PM integrity assays in Figure 6 were performed as described (Omnus et al., 2016;

Collado et al., 2019). Yeast strains were grown at $26^{\circ} \mathrm{C}$ to midlog phase, then kept at $26^{\circ} \mathrm{C}$ or shifted to either $42^{\circ} \mathrm{C}$ for 15 min. $1 \mathrm{OD}_{600}$ equivalent of cells was pelleted, resuspended in PBST (0.01\% Tween 20$)$, and stained with propidium iodide (Sigma) for 15 min. Cells were then washed twice with PBST and analysed by flow cytometry on a BD Accuri C6 flow cytometer. For flow cytometry analysis, 50,000 cells were counted for each sample from three independent experiments and combined for a total analysis of 150,000 cells. Background was determined by analysing each of the cell strains at the indicated temperatures prior to staining with propidium iodide.

\section{Quantification and Statistical Analysis}

Statistical analysis was carried out using GraphPad Prism 8. To compare the mean of two groups, an unpaired two-tailed t test was used. To compare the mean of multiple groups, we used one-way ANOVA followed by Tukey-Kramer multiple comparisons. 


\section{Acknowledgements}

We thank Scott Emr, Jeremy Thorner, Todd Graham, Yuxin Mao, and Greg Fairn for strains and plasmids. We also thank Ruben Fernandez-Busnadiego, Robbie Loewith, Tim Levine, Taki Nishimura, and Bailey Hewlett for helpful discussions. C.J.S. is supported by MRC funding to the MRC LMCB University Unit at UCL, award code MC_UU_00012/6.

\section{Availability of data and materials}

Materials used in this study are available from the corresponding author on request.

\section{Contributions}

F.B.T., D.J.O., J.M.B., G.H.C.C., N.K., and C.J.S. designed and performed experiments; F.B.T., N.K., and C.J.S. analysed the data and wrote the manuscript. All authors discussed the results and commented on the manuscript.

\section{Competing interests}

The authors declare that they have no competing interests. 


\section{References}

Aguilar, P.S., A. Engel, and P. Walter. 2007. The plasma membrane proteins Prm1 and Fig1 ascertain fidelity of membrane fusion during yeast mating. Mol Biol Cell. 18:547-556.

Atkinson, K.D., B. Jensen, A.I. Kolat, E.M. Storm, S.A. Henry, and S. Fogel. 1980. Yeast mutants auxotrophic for choline or ethanolamine. J Bacteriol. 141:558564.

Audhya, A., and S.D. Emr. 2002. Stt4 PI 4-kinase localizes to the plasma membrane and functions in the Pkc1-mediated MAP kinase cascade. Dev Cell. 2:593-605.

Audhya, A., M. Foti, and S.D. Emr. 2000. Distinct roles for the yeast phosphatidylinositol 4-kinases, Stt4p and Pik1p, in secretion, cell growth, and organelle membrane dynamics. Mol Biol Cell. 11:2673-2689.

Balla, T., N. Sengupta, and Y.J. Kim. 2020. Lipid synthesis and transport are coupled to regulate membrane lipid dynamics in the endoplasmic reticulum. Biochim Biophys Acta Mol Cell Biol Lipids. 1865:158461.

Barnard, E., N.V. McFerran, A. Trudgett, J. Nelson, and D.J. Timson. 2008. Detection and localisation of protein-protein interactions in Saccharomyces cerevisiae using a split-GFP method. Fungal Genet Biol. 45:597-604.

Benink, H.A., and W.M. Bement. 2005. Concentric zones of active RhoA and Cdc42 around single cell wounds. J Cell Biol. 168:429-439.

Bian, X., and P. De Camilli. 2019. In Vitro Assays to Measure the Membrane Tethering and Lipid Transport Activities of the Extended Synaptotagmins. Methods Mol Biol. 1949:201-212.

Bian, X., Y. Saheki, and P. De Camilli. 2018. Ca(2+) releases E-Syt1 autoinhibition to couple ER-plasma membrane tethering with lipid transport. Embo j. 37:219234.

Bigay, J., and B. Antonny. 2012. Curvature, lipid packing, and electrostatics of membrane organelles: defining cellular territories in determining specificity. Dev Cell. 23:886-895.

Boye, T.L., K. Maeda, W. Pezeshkian, S.L. Sønder, S.C. Haeger, V. Gerke, A.C. Simonsen, and J. Nylandsted. 2017. Annexin A4 and A6 induce membrane curvature and constriction during cell membrane repair. Nat Commun. 8:1623.

Brachmann, C.B., A. Davies, G.J. Cost, E. Caputo, J. Li, P. Hieter, and J.D. Boeke. 1998. Designer deletion strains derived from Saccharomyces cerevisiae S288C: a useful set of strains and plasmids for PCR-mediated gene disruption and other applications. Yeast. 14:115-132.

Casamayor, A., P.D. Torrance, T. Kobayashi, J. Thorner, and D.R. Alessi. 1999. Functional counterparts of mammalian protein kinases PDK1 and SGK in budding yeast. Curr Biol. 9:186-197.

Chang, C.L., Y.J. Chen, and J. Liou. 2017. ER-plasma membrane junctions: Why and how do we study them? Biochim Biophys Acta Mol Cell Res. 1864:1494-1506.

Chang, C.L., T.S. Hsieh, T.T. Yang, K.G. Rothberg, D.B. Azizoglu, E. Volk, J.C. Liao, and J. Liou. 2013. Feedback regulation of receptor-induced $\mathrm{Ca} 2+$ signaling mediated by E-Syt1 and Nir2 at endoplasmic reticulum-plasma membrane junctions. Cell Rep. 5:813-825.

Chapman, E.R. 2008. How does synaptotagmin trigger neurotransmitter release? Annu Rev Biochem. 77:615-641.

Cheng, X., X. Zhang, Q. Gao, M. Ali Samie, M. Azar, W.L. Tsang, L. Dong, N. Sahoo, X. Li, Y. Zhuo, A.G. Garrity, X. Wang, M. Ferrer, J. Dowling, L. Xu, R. Han, and $\mathrm{H}$. $\mathrm{Xu}$. 2014. The intracellular $\mathrm{Ca}^{2+}$ channel MCOLN1 is required for sarcolemma repair to prevent muscular dystrophy. Nat Med. 20:1187-1192. 
Cho, K.J., D. van der Hoeven, Y. Zhou, M. Maekawa, X. Ma, W. Chen, G.D. Fairn, and J.F. Hancock. 2016. Inhibition of Acid Sphingomyelinase Depletes Cellular Phosphatidylserine and Mislocalizes K-Ras from the Plasma Membrane. Mol Cell Biol. 36:363-374.

Chung, J., F. Nakatsu, J.M. Baskin, and P. De Camilli. 2015. Plasticity of PI4KIIlalpha interactions at the plasma membrane. EMBO Rep. 16:312-320.

Clark, J., K.E. Anderson, V. Juvin, T.S. Smith, F. Karpe, M.J. Wakelam, L.R. Stephens, and P.T. Hawkins. 2011. Quantification of PtdlnsP3 molecular species in cells and tissues by mass spectrometry. Nat Methods. 8:267-272.

Collado, J., M. Kalemanov, F. Campelo, C. Bourgoint, F. Thomas, R. Loewith, A. Martinez-Sanchez, W. Baumeister, C.J. Stefan, and R. FernandezBusnadiego. 2019. Tricalbin-Mediated Contact Sites Control ER Curvature to Maintain Plasma Membrane Integrity. Dev Cell. 51:476-487.e477.

D'Ambrosio, J.M., V. Albanèse, N.F. Lipp, L. Fleuriot, D. Debayle, G. Drin, and A. Čopič. 2020. Osh6 requires Ist2 for localization to ER-PM contacts and efficient phosphatidylserine transport in budding yeast. J Cell Sci. 133.

Detrait, E.R., S. Yoo, C.S. Eddleman, M. Fukuda, G.D. Bittner, and H.M. Fishman. 2000. Plasmalemmal repair of severed neurites of $P C 12$ cells requires $\mathrm{Ca}(2+)$ and synaptotagmin. J Neurosci Res. 62:566-573.

Dickson, E.J., J.B. Jensen, O. Vivas, M. Kruse, A.E. Traynor-Kaplan, and B. Hille. 2016. Dynamic formation of ER-PM junctions presents a lipid phosphatase to regulate phosphoinositides. J Cell Biol. 213:33-48.

Ejsing, C.S., J.L. Sampaio, V. Surendranath, E. Duchoslav, K. Ekroos, R.W. Klemm, K. Simons, and A. Shevchenko. 2009. Global analysis of the yeast lipidome by quantitative shotgun mass spectrometry. Proc Natl Acad Sci U S A. 106:21362141.

Fadok, V.A., D.R. Voelker, P.A. Campbell, J.J. Cohen, D.L. Bratton, and P.M. Henson. 1992. Exposure of phosphatidylserine on the surface of apoptotic lymphocytes triggers specific recognition and removal by macrophages. $J$ Immunol. 148:2207-2216.

Fairn, G.D., M. Hermansson, P. Somerharju, and S. Grinstein. 2011. Phosphatidylserine is polarized and required for proper Cdc42 localization and for development of cell polarity. Nat Cell Biol. 13:1424-1430.

Fairn, G.D., K. Ogata, R.J. Botelho, P.D. Stahl, R.A. Anderson, P. De Camilli, T. Meyer, S. Wodak, and S. Grinstein. 2009. An electrostatic switch displaces phosphatidylinositol phosphate kinases from the membrane during phagocytosis. J Cell Biol. 187:701-714.

Fernandez-Busnadiego, R., Y. Saheki, and P. De Camilli. 2015. Three-dimensional architecture of extended synaptotagmin-mediated endoplasmic reticulumplasma membrane contact sites. Proc Natl Acad Sci U S A. 112:E2004-2013.

Fidler, D.R., S.E. Murphy, K. Courtis, P. Antonoudiou, R. El-Tohamy, J. lent, and T.P. Levine. 2016. Using HHsearch to tackle proteins of unknown function: A pilot study with PH domains. Traffic. 17:1214-1226.

Friant, S., R. Lombardi, T. Schmelzle, M.N. Hall, and H. Riezman. 2001. Sphingoid base signaling via Pkh kinases is required for endocytosis in yeast. Embo $j$. 20:6783-6792.

Gallo, A., L. Danglot, F. Giordano, B. Hewlett, T. Binz, C. Vannier, and T. Galli. 2020. Role of the Sec22b-E-Syt complex in neurite growth and ramification. J Cell Sci. 133.

Gatta, A.T., L.H. Wong, Y.Y. Sere, D.M. Calderón-Noreña, S. Cockcroft, A.K. Menon, and T.P. Levine. 2015. A new family of StART domain proteins at membrane contact sites has a role in ER-PM sterol transport. Elife. 4. 
Giordano, F., Y. Saheki, O. Idevall-Hagren, S.F. Colombo, M. Pirruccello, I. Milosevic, E.O. Gracheva, S.N. Bagriantsev, N. Borgese, and P. De Camilli. 2013. $\mathrm{PI}(4,5) \mathrm{P}(2)$-dependent and $\mathrm{Ca}(2+)$-regulated ER-PM interactions mediated by the extended synaptotagmins. Cell. 153:1494-1509.

Haupt, A., and N. Minc. 2017. Gradients of phosphatidylserine contribute to plasma membrane charge localization and cell polarity in fission yeast. Mol Biol Cell. 28:210-220.

Heras-Martínez, G.L., V. Calleja, R. Bailly, J. Dessolin, B. Larijani, and J. RequejoIsidro. 2019. A Complex Interplay of Anionic Phospholipid Binding Regulates 3'-Phosphoinositide-Dependent-Kinase-1 Homodimer Activation. Sci Rep. 9:14527.

Herdman, C., M.G. Tremblay, P.K. Mishra, and T. Moss. 2014. Loss of Extended Synaptotagmins ESyt2 and ESyt3 does not affect mouse development or viability, but in vitro cell migration and survival under stress are affected. Cell Cycle. 13:2616-2625.

Herzog, R., K. Schuhmann, D. Schwudke, J.L. Sampaio, S.R. Bornstein, M. Schroeder, and A. Shevchenko. 2012. LipidXplorer: a software for consensual cross-platform lipidomics. PLoS One. 7:e29851.

Herzog, R., D. Schwudke, K. Schuhmann, J.L. Sampaio, S.R. Bornstein, M. Schroeder, and A. Shevchenko. 2011. A novel informatics concept for highthroughput shotgun lipidomics based on the molecular fragmentation query language. Genome Biol. 12:R8.

Hoffmann, P.C., T.A.M. Bharat, M.R. Wozny, J. Boulanger, E.A. Miller, and W. Kukulski. 2019. Tricalbins Contribute to Cellular Lipid Flux and Form Curved ER-PM Contacts that Are Bridged by Rod-Shaped Structures. Developmental cell. 51:488-502.e488.

Holmes, W.R., L. Liao, W. Bement, and L. Edelstein-Keshet. 2015. Modeling the roles of protein kinase $C \beta$ and $\eta$ in single-cell wound repair. Mol Biol Cell. 26:41004108.

Holthuis, J.C., and A.K. Menon. 2014. Lipid landscapes and pipelines in membrane homeostasis. Nature. 510:48-57.

Horn, A., and J.K. Jaiswal. 2018. Cellular mechanisms and signals that coordinate plasma membrane repair. Cell Mol Life Sci. 75:3751-3770.

Horn, A., and J.K. Jaiswal. 2019. Structural and signaling role of lipids in plasma membrane repair. Curr Top Membr. 84:67-98.

Hsuan, J., and S. Cockcroft. 2001. The PITP family of phosphatidylinositol transfer proteins. Genome Biol. 2:Reviews3011.

Hua, Z., P. Fatheddin, and T.R. Graham. 2002. An essential subfamily of Drs2p-related P-type ATPases is required for protein trafficking between Golgi complex and endosomal/vacuolar system. Mol Biol Cell. 13:3162-3177.

Hui, E., C.P. Johnson, J. Yao, F.M. Dunning, and E.R. Chapman. 2009. Synaptotagmin-mediated bending of the target membrane is a critical step in $\mathrm{Ca}(2+)$-regulated fusion. Cell. 138:709-721.

Idevall-Hagren, O., A. Lu, B. Xie, and P. De Camilli. 2015. Triggered Ca2+ influx is required for extended synaptotagmin 1-induced ER-plasma membrane tethering. Embo j. 34:2291-2305.

lida, H., H. Nakamura, T. Ono, M.S. Okumura, and Y. Anraku. 1994. MID1, a novel Saccharomyces cerevisiae gene encoding a plasma membrane protein, is required for $\mathrm{Ca} 2+$ influx and mating. Mol Cell Biol. 14:8259-8271.

Ikeda, A., P. Schlarmann, K. Kurokawa, A. Nakano, H. Riezman, and K. Funato. 2020. Tricalbins Are Required for Non-vesicular Ceramide Transport at ER-Golgi Contacts and Modulate Lipid Droplet Biogenesis. iScience. 23:101603. 
Jaiswal, J.K. 2001. Calcium - how and why? J Biosci. 26:357-363.

Jorgensen, J.R., R. Tei, J.M. Baskin, A.H. Michel, B. Kornmann, and S.D. Emr. 2020. ESCRT-III and ER-PM contacts maintain lipid homeostasis. Mol Biol Cell. 31:1302-1313.

Kaplan, M.R., and R.D. Simoni. 1985. Intracellular transport of phosphatidylcholine to the plasma membrane. J Cell Biol. 101:441-445.

Kato, T., A. Kubo, T. Nagayama, S. Kume, C. Tanaka, Y. Nakayama, K. lida, and H. lida. 2017. Genetic analysis of the regulation of the voltage-gated calcium channel homolog Cch1 by the $\mathrm{y}$ subunit homolog Ecm7 and cortical ER protein Scs2 in yeast. PLoS One. 12:e0181436.

Kikuma, K., X. Li, D. Kim, D. Sutter, and D.K. Dickman. 2017. Extended Synaptotagmin Localizes to Presynaptic ER and Promotes Neurotransmission and Synaptic Growth in Drosophila. Genetics. 207:993-1006.

Kim, J.Y., B.K. Choi, M.G. Choi, S.A. Kim, Y. Lai, Y.K. Shin, and N.K. Lee. 2012. Solution single-vesicle assay reveals PIP2-mediated sequential actions of synaptotagmin-1 on SNAREs. Embo j. 31:2144-2155.

Klemm, R.W., C.S. Ejsing, M.A. Surma, H.J. Kaiser, M.J. Gerl, J.L. Sampaio, Q. de Robillard, C. Ferguson, T.J. Proszynski, A. Shevchenko, and K. Simons. 2009. Segregation of sphingolipids and sterols during formation of secretory vesicles at the trans-Golgi network. J Cell Biol. 185:601-612.

Klose, C., M.A. Surma, M.J. Gerl, F. Meyenhofer, A. Shevchenko, and K. Simons. 2012. Flexibility of a eukaryotic lipidome--insights from yeast lipidomics. PLoS One. 7:e35063.

Koerdt, S.N., A.P.K. Ashraf, and V. Gerke. 2019. Annexins and plasma membrane repair. Curr Top Membr. 84:43-65.

Kopec, K.O., V. Alva, and A.N. Lupas. 2010. Homology of SMP domains to the TULIP superfamily of lipid-binding proteins provides a structural basis for lipid exchange between ER and mitochondria. Bioinformatics. 26:1927-1931.

Lee, I., and W. Hong. 2006. Diverse membrane-associated proteins contain a novel SMP domain. Faseb j. 20:202-206.

Lek, A., F.J. Evesson, F.A. Lemckert, G.M. Redpath, A.K. Lueders, L. Turnbull, C.B. Whitchurch, K.N. North, and S.T. Cooper. 2013. Calpains, cleaved minidysferlinC72, and L-type channels underpin calcium-dependent muscle membrane repair. J Neurosci. 33:5085-5094.

Levin, D.E. 2005. Cell wall integrity signaling in Saccharomyces cerevisiae. Microbiol Mol Biol Rev. 69:262-291.

Lingwood, D., and K. Simons. 2010. Lipid rafts as a membrane-organizing principle. Science. 327:46-50.

Loewen, C.J., B.P. Young, S. Tavassoli, and T.P. Levine. 2007. Inheritance of cortical ER in yeast is required for normal septin organization. J Cell Biol. 179:467-483.

Loewen, C.J.R., and T.P. Levine. 2005. A highly conserved binding site in vesicleassociated membrane protein-associated protein (VAP) for the FFAT motif of lipid-binding proteins. The Journal of biological chemistry. 280:14097-14104.

Longtine, M.S., A. McKenzie, 3rd, D.J. Demarini, N.G. Shah, A. Wach, A. Brachat, P. Philippsen, and J.R. Pringle. 1998. Additional modules for versatile and economical PCR-based gene deletion and modification in Saccharomyces cerevisiae. Yeast. 14:953-961.

Lucas, N., and W. Cho. 2011. Phosphatidylserine binding is essential for plasma membrane recruitment and signaling function of 3-phosphoinositide-dependent kinase-1. J Biol Chem. 286:41265-41272. 
Luo, X., D.J. Wasilko, Y. Liu, J. Sun, X. Wu, Z.Q. Luo, and Y. Mao. 2015. Structure of the Legionella Virulence Factor, SidC Reveals a Unique PI(4)P-Specific Binding Domain Essential for Its Targeting to the Bacterial Phagosome. PLoS Pathog. 11:e1004965.

Manford, A.G., C.J. Stefan, H.L. Yuan, J.A. Macgurn, and S.D. Emr. 2012. ER-toplasma membrane tethering proteins regulate cell signaling and $E R$ morphology. Dev Cell. 23:1129-1140.

Matsuo, Y., E. Fisher, J. Patton-Vogt, and S. Marcus. 2007. Functional characterization of the fission yeast phosphatidylserine synthase gene, pps1, reveals novel cellular functions for phosphatidylserine. Eukaryot Cell. 6:2092-2101.

Middel, V., L. Zhou, M. Takamiya, T. Beil, M. Shahid, U. Roostalu, C. Grabher, S. Rastegar, M. Reischl, G.U. Nienhaus, and U. Strähle. 2016. Dysferlin-mediated phosphatidylserine sorting engages macrophages in sarcolemma repair. Nat Commun. 7:12875.

Mioka, T., K. Fujimura-Kamada, N. Mizugaki, T. Kishimoto, T. Sano, H. Nunome, D.E. Williams, R.J. Andersen, and K. Tanaka. 2018. Phospholipid flippases and Sfk1p, a novel regulator of phospholipid asymmetry, contribute to low permeability of the plasma membrane. Mol Biol Cell. 29:1203-1218.

Muir, A., S. Ramachandran, F.M. Roelants, G. Timmons, and J. Thorner. 2014. TORC2-dependent protein kinase Ypk1 phosphorylates ceramide synthase to stimulate synthesis of complex sphingolipids. Elife. 3.

Muller, E.M., E.G. Locke, and K.W. Cunningham. 2001. Differential regulation of two $\mathrm{Ca}(2+)$ influx systems by pheromone signaling in Saccharomyces cerevisiae. Genetics. 159:1527-1538.

Nath, V.R., S. Mishra, B. Basak, D. Trivedi, and P. Raghu. 2020. Extended synaptotagmin regulates membrane contact site structure and lipid transfer function in vivo. EMBO Rep. $21: e 50264$.

Nishimura, T., M. Gecht, R. Covino, G. Hummer, M.A. Surma, C. Klose, H. Arai, N. Kono, and C.J. Stefan. 2019. Osh Proteins Control Nanoscale Lipid Organization Necessary for PI(4,5)P2 Synthesis. Mol Cell. 75:10431057.e1048.

Nishimura, T., and C.J. Stefan. 2020. Specialized ER membrane domains for lipid metabolism and transport. Biochim Biophys Acta Mol Cell Biol Lipids. 1865:158492.

Omnus, D.J., A.G. Manford, J.M. Bader, S.D. Emr, and C.J. Stefan. 2016. Phosphoinositide kinase signaling controls ER-PM cross-talk. Mol Biol Cell. 27:1170-1180.

Pichler, H., B. Gaigg, C. Hrastnik, G. Achleitner, S.D. Kohlwein, G. Zellnig, A. Perktold, and G. Daum. 2001. A subfraction of the yeast endoplasmic reticulum associates with the plasma membrane and has a high capacity to synthesize lipids. Eur J Biochem. 268:2351-2361.

Qian, T., C. Li, R. He, C. Wan, Y. Liu, and H. Yu. 2021. Calcium-dependent and independent lipid transfer mediated by tricalbins in yeast. J Biol Chem:100729.

Quon, E., Y.Y. Sere, N. Chauhan, J. Johansen, D.P. Sullivan, J.S. Dittman, W.J. Rice, R.B. Chan, G. Di Paolo, C.T. Beh, and A.K. Menon. 2018. Endoplasmic reticulum-plasma membrane contact sites integrate sterol and phospholipid regulation. PLoS Biol. 16:e2003864.

Robinson, J.S., D.J. Klionsky, L.M. Banta, and S.D. Emr. 1988. Protein sorting in Saccharomyces cerevisiae: isolation of mutants defective in the delivery and processing of multiple vacuolar hydrolases. Molecular and cellular biology. 8:4936-4948. 
Roelants, F.M., D.K. Breslow, A. Muir, J.S. Weissman, and J. Thorner. 2011. Protein kinase Ypk1 phosphorylates regulatory proteins Orm1 and Orm2 to control sphingolipid homeostasis in Saccharomyces cerevisiae. Proc Natl Acad Sci U $S$ A. 108:19222-19227.

Roelants, F.M., P.D. Torrance, N. Bezman, and J. Thorner. 2002. Pkh1 and Pkh2 differentially phosphorylate and activate $\mathrm{Ypk} 1$ and $\mathrm{Ykr} 2$ and define protein kinase modules required for maintenance of cell wall integrity. Mol Biol Cell. 13:3005-3028.

Saheki, Y., X. Bian, C.M. Schauder, Y. Sawaki, M.A. Surma, C. Klose, F. Pincet, K.M. Reinisch, and P. De Camilli. 2016. Control of plasma membrane lipid homeostasis by the extended synaptotagmins. Nat Cell Biol. 18:504-515.

Sartorel, E., C. Unlu, M. Jose, A. Massoni-Laporte, J. Meca, J.B. Sibarita, and D. McCusker. 2018. Phosphatidylserine and GTPase activation control Cdc42 nanoclustering to counter dissipative diffusion. Mol Biol Cell. 29:1299-1310.

Schauder, C.M., X. Wu, Y. Saheki, P. Narayanaswamy, F. Torta, M.R. Wenk, P. De Camilli, and K.M. Reinisch. 2014. Structure of a lipid-bound extended synaptotagmin indicates a role in lipid transfer. Nature. 510:552-555.

Schindelin, J., I. Arganda-Carreras, E. Frise, V. Kaynig, M. Longair, T. Pietzsch, S. Preibisch, C. Rueden, S. Saalfeld, B. Schmid, J.Y. Tinevez, D.J. White, V. Hartenstein, K. Eliceiri, P. Tomancak, and A. Cardona. 2012. Fiji: an opensource platform for biological-image analysis. Nat Methods. 9:676-682.

Schneiter, R., B. Brügger, R. Sandhoff, G. Zellnig, A. Leber, M. Lampl, K. Athenstaedt, C. Hrastnik, S. Eder, G. Daum, F. Paltauf, F.T. Wieland, and S.D. Kohlwein. 1999. Electrospray ionization tandem mass spectrometry (ESI-MS/MS) analysis of the lipid molecular species composition of yeast subcellular membranes reveals acyl chain-based sorting/remodeling of distinct molecular species en route to the plasma membrane. J Cell Biol. 146:741-754.

Sclip, A., T. Bacaj, L.R. Giam, and T.C. Sudhof. 2016. Extended Synaptotagmin (ESyt) Triple Knock-Out Mice Are Viable and Fertile without Obvious Endoplasmic Reticulum Dysfunction. PLoS One. 11:e0158295.

Sikorski, R.S., and P. Hieter. 1989. A system of shuttle vectors and yeast host strains designed for efficient manipulation of DNA in Saccharomyces cerevisiae. Genetics. 122:19-27.

Stefan, C.J., A. Audhya, and S.D. Emr. 2002. The yeast synaptojanin-like proteins control the cellular distribution of phosphatidylinositol $(4,5)$-bisphosphate. Mol Biol Cell. 13:542-557.

Südhof, T.C. 2002. Synaptotagmins: why so many? J Biol Chem. 277:7629-7632.

Sun, Y., R. Taniguchi, D. Tanoue, T. Yamaji, H. Takematsu, K. Mori, T. Fujita, T. Kawasaki, and Y. Kozutsumi. 2000. Sli2 (Ypk1), a homologue of mammalian protein kinase SGK, is a downstream kinase in the sphingolipid-mediated signaling pathway of yeast. Mol Cell Biol. 20:4411-4419.

Surma, M.A., R. Herzog, A. Vasilj, C. Klose, N. Christinat, D. Morin-Rivron, K. Simons, M. Masoodi, and J.L. Sampaio. 2015. An automated shotgun lipidomics platform for high throughput, comprehensive, and quantitative analysis of blood plasma intact lipids. Eur J Lipid Sci Technol. 117:1540-1549.

Toulmay, A., and W.A. Prinz. 2012. A conserved membrane-binding domain targets proteins to organelle contact sites. J Cell Sci. 125:49-58.

Tremblay, M.G., and T. Moss. 2016. Loss of all 3 Extended Synaptotagmins does not affect normal mouse development, viability or fertility. Cell Cycle. 15:23602366. 
Urbani, L., and R.D. Simoni. 1990. Cholesterol and vesicular stomatitis virus G protein take separate routes from the endoplasmic reticulum to the plasma membrane. J Biol Chem. 265:1919-1923.

van den Bogaart, G., S. Thutupalli, J.H. Risselada, K. Meyenberg, M. Holt, D. Riedel, U. Diederichsen, S. Herminghaus, H. Grubmüller, and R. Jahn. 2011. Synaptotagmin-1 may be a distance regulator acting upstream of SNARE nucleation. Nat Struct Mol Biol. 18:805-812.

van Meer, G., D.R. Voelker, and G.W. Feigenson. 2008. Membrane lipids: where they are and how they behave. Nat Rev Mol Cell Biol. 9:112-124.

Vance, J.E., E.J. Aasman, and R. Szarka. 1991. Brefeldin A does not inhibit the movement of phosphatidylethanolamine from its sites for synthesis to the cell surface. J Biol Chem. 266:8241-8247.

Vonkova, I., A.E. Saliba, S. Deghou, K. Anand, S. Ceschia, T. Doerks, A. Galih, K.G. Kugler, K. Maeda, V. Rybin, V. van Noort, J. Ellenberg, P. Bork, and A.C. Gavin. 2015. Lipid Cooperativity as a General Membrane-Recruitment Principle for PH Domains. Cell Rep. 12:1519-1530.

Wang, Y., P. Yuan, A. Grabon, A. Tripathi, D. Lee, M. Rodriguez, M. Lönnfors, M. Eisenberg-Bord, Z. Wang, S. Man Lam, M. Schuldiner, and V.A. Bankaitis. 2020. Noncanonical regulation of phosphatidylserine metabolism by a Sec14like protein and a lipid kinase. J Cell Biol. 219.

Wenk, M.R., L. Lucast, G. Di Paolo, A.J. Romanelli, S.F. Suchy, R.L. Nussbaum, G.W. Cline, G.I. Shulman, W. McMurray, and P. De Camilli. 2003. Phosphoinositide profiling in complex lipid mixtures using electrospray ionization mass spectrometry. Nat Biotechnol. 21:813-817.

Wong, L.H., A.T. Gatta, and T.P. Levine. 2019. Lipid transfer proteins: the lipid commute via shuttles, bridges and tubes. Nat Rev Mol Cell Biol. 20:85-101.

Wong, L.H., and T.P. Levine. 2017. Tubular lipid binding proteins (TULIPs) growing everywhere. Biochim Biophys Acta Mol Cell Res. 1864:1439-1449.

Yeung, T., G.E. Gilbert, J. Shi, J. Silvius, A. Kapus, and S. Grinstein. 2008. Membrane phosphatidylserine regulates surface charge and protein localization. Science. 319:210-213.

Yu, H., Y. Liu, D.R. Gulbranson, A. Paine, S.S. Rathore, and J. Shen. 2016. Extended synaptotagmins are $\mathrm{Ca2+-dependent} \mathrm{lipid} \mathrm{transfer} \mathrm{proteins} \mathrm{at} \mathrm{membrane}$ contact sites. Proc Natl Acad Sci U S A. 113:4362-4367.

Zimmerman, A.N., and W.C. Hülsmann. 1966. Paradoxical influence of calcium ions on the permeability of the cell membranes of the isolated rat heart. Nature. 211:646-647. 


\section{Figure Legends}

Figure 1. Cytoplasmic calcium levels are increased in $s c s 2 / 22 \Delta$ ist2 $\Delta$ and $\Delta$ tether mutant cells.

(A) Schematic representations of ER-PM tethering proteins found in budding yeast. These include the tricalbins (Tcb), Scs2 and Scs22, Ist2 and Lam proteins. This study is focused on elucidating specific roles of the Tcb proteins in PM homeostasis. Abbreviations: SMP, Synaptotagmin-like mitochondrial-lipid-binding domain; C2, C2 domain; MSP, Major sperm protein domain; PB, Polybasic stretch, StART, StARrelated lipid-transfer domain; $\mathrm{PH}$, Pleckstrin homology domain. (B) Mean fluorescence intensity of cytoplasmic GCaMP3 reporter of wild type, $t c b 1 / 2 / 3 \Delta, s c s 2 / 22 \Delta$ ist2 $\Delta$ and $\Delta$ tether cells as measured by flow cytometry $(100,000$ cells measured per experiment). Data represents mean \pm standard deviation from three independent experiments. ${ }^{* * *}$ $p>0.001$. (C) Quantitation of GCaMP3 signal in the cytosol of wild type, tcb1/2/3 $\operatorname{scs} 2 / 22 \Delta$ ist2 $\Delta$ and $\Delta$ tether cells measured by fluorescence microscopy. Data represents mean \pm standard deviation. Total number of cells analysed in three independent experiments: wild type $\mathrm{n}=109, \operatorname{tcb} 1 / 2 / 3 \Delta \mathrm{n}=103, \operatorname{scs} 2 / 22 \Delta$ ist $2 \Delta \mathrm{n}=97$, $\Delta$ tether $n=100 .{ }^{* \star \star \star} p>0.0001$. Also see Figure $\mathbf{S 1}$.

\section{Figure 2. Tricalbin proteins regulate phosphoinositide homeostasis at the PM.}

(A) Schematic representation of $\mathrm{PI} 4 \mathrm{P}$ and $\mathrm{PI}(4,5)_{2}$ production at the $\mathrm{PM}$ and the kinases involved. (B) PI4P (GFP-P4C) and PI(4,5) $\mathrm{P}_{2}$ (GFP-2xPH $\mathrm{PLC}_{\delta}$ ) FLARE localisation in wild type, $t c b 1 / 2 / 3 \Delta, s c s 2 / 22 \Delta$ ist2 $\Delta$ and $\Delta$ tether cells. Scale bars, $4 \mu \mathrm{m}$. (C) Quantitation of GFP-P4C intensity at the PM of the mother cell. Data represents mean \pm standard deviation. Total number of cells analysed in three independent experiments: wild type $n=104, t c b 1 / 2 / 3 \Delta n=102, \operatorname{scs} 2 / 22 \Delta$ ist $2 \Delta n=107, \Delta$ tether $n=105$. ${ }^{* \star \star *} p>0.0001$. (D) Quantitation of GFP-2xPH $\mathrm{PLC}$ intensity at the PM of the mother 
cell. Data represents mean \pm standard deviation. Total number of cells analysed in three independent experiments: wild type $n=146, t c b 1 / 2 / 3 \Delta n=149, \operatorname{scs} 2 / 22 \Delta$ ist2 $\Delta$ $\mathrm{n}=146, \Delta$ tether $\mathrm{n}=147) .{ }^{\star \star \star \star} \mathrm{p}>0.0001 .(\mathbf{E}$ and $\mathbf{F})$ Lipidomic analysis of PIP $36: 1$ and PIP2 36:1 species in wild type, tcb1/2/3s, scs2/22 $\Delta$ ist2 $\Delta$ and $\Delta$ tether cells. Data represents mean \pm standard deviation $(\mathrm{N}=5) .{ }^{* \star} \mathrm{p}>0.01,{ }^{* *} \mathrm{p}>0.001$.

Also see Figure S2.

Figure 3. Tricalbin proteins regulate phospholipid homeostasis at the PM.

(A) Schematic representation of PS, PE, and PC production and the enzymes involved. (B) PS FLARE (GFP-Lact-C2) localisation in wild type, tcb1/2/3 $\Delta$, scs2/22 $\Delta$ ist2 $\Delta$ and $\Delta$ tether cells. Scale bars, $4 \mu \mathrm{m}$. (C) Quantitation of relative GFP-Lact-C2 intensity at the PM of the mother cell. Data represents mean \pm standard deviation. Total number of cells analysed in three independent experiments: wild type $n=196, t c b 1 / 2 / 3 \Delta n=194$, scs2/22 $\Delta$ ist $2 \Delta \mathrm{n}=187, \Delta$ tether $\mathrm{n}=184 .{ }^{* * \star *} \mathrm{p}>0.0001$. (D, E, and F) Lipidomic analyses

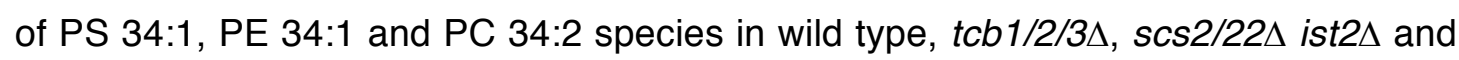
$\Delta$ tether cells. Data represents mean \pm standard deviation $(\mathrm{N}=3) .{ }^{*} \mathrm{p}>0.1,{ }^{* *} \mathrm{p}>0.01$. Also see Figure S3.

Figure 4. Tcb3 co-localises with the integral PM protein Sfk1.

(A) Cartoon displaying the bi-molecular fluorescence (BiFC) split GFP assay to assess Tcb3-Sfk1 proximity. The N-terminal half of GFP $\left(G_{F P}\right)$ and the C-terminal half of GFP (GFP ) form a fluorescent GFP only when their fusion partners, in this case Tcb3

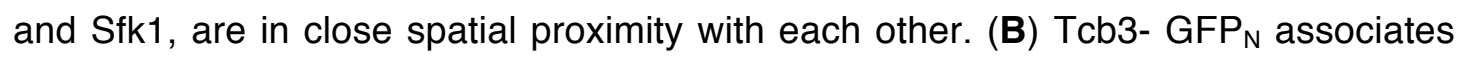
with Sfk1-GFP but not with a mutant Sfk1 lacking its cytoplasmic C-terminus (Sfk $1^{\Delta 286-}$ ${ }^{353}$-GFP $)$. The pseudo-colored images indicate the scale of specific BiFC signals (blue, moderate; red, strong). Scale bars, $4 \mu \mathrm{m}$ (A) Cortical localisation of Tcb3-GFP 
and Sfk1-mCherry at $26^{\circ} \mathrm{C}$ or after $10 \mathrm{~min}$ at $42^{\circ} \mathrm{C}$. Scale bars, $4 \mu \mathrm{m}$ (B) Quantitation of Tcb3-GFP and Sfk1-mCherry co-localisation (Pearson's coefficient) at $26^{\circ} \mathrm{C}$ or after 10 min at $42^{\circ} \mathrm{C}$. Data represents mean \pm standard deviation. Total number of cells analysed in three independent experiments: wild type $n=82, \operatorname{tcb} 1 / 2 / 3 \Delta n=75) .{ }^{\star \star \star \star} p>$ 0.0001. Also see Figure S4.

Figure 5. Tricalbin proteins control phosphatidylserine distribution and Pkh1 localisation under heat shock conditions.

(A) PS FLARE (GFP-Lact-C2) localisation in wild type and $t c b 1 / 2 / 3 \Delta$ cells at $26^{\circ} \mathrm{C}$ or after $10 \mathrm{~min}$ at $42^{\circ} \mathrm{C}$. Scale bar, $4 \mu \mathrm{m}$. (B) Quantitation of relative GFP-Lact-C2 levels at the PM at $26^{\circ} \mathrm{C}$ and after $10 \mathrm{~min}$ at $42^{\circ} \mathrm{C}$ in wild type and $t c b 1 / 2 / 3 \Delta$ cells. Data represents mean \pm standard deviation. Total number of cells analysed in three independent experiments: wild type $26^{\circ} \mathrm{C} n=153$, wild type 10 min $42^{\circ} \mathrm{C} n=152$, tcb 1/2/3 $26^{\circ} \mathrm{C} n=152, t c b 1 / 2 / 3 \Delta 10 \min 42^{\circ} \mathrm{C} n=151$ cells. ${ }^{* * *} \mathrm{p}>0.0001$. (C) GFPPkh1 localisation in wild type and $t c b 1 / 2 / 3 \Delta$ cells at $26^{\circ} \mathrm{C}$ or after 10 min at $42^{\circ} \mathrm{C}$. White arrows show examples of GFP-Pkh1 cortical patches in wild type cells at $42^{\circ} \mathrm{C}$. Scale bar $4 \mu \mathrm{m}$. (D) Quantitation of the number of GFP-Pkh1 foci per cell at $26^{\circ} \mathrm{C}$ and after 10 min at $42^{\circ} \mathrm{C}$ in wild type and $t c b 1 / 2 / 3 \Delta$ cells. Total number of cells analysed in three independent experiments: wild type $26^{\circ} \mathrm{C} n=229$, wild type 10 min $42^{\circ} \mathrm{C} n=216$, tcb 1/2/3 $26^{\circ} \mathrm{C} n=196, t c b 1 / 2 / 3 \Delta 10 \min 42^{\circ} \mathrm{C} n=173$ cells from three independent experiments. ${ }^{* * *} p>0.0001$. Also see Figure S5.

Figure 6. The SMP domain of $\mathrm{Tcb3}$ is required for phosphatidylserine homeostasis and PM integrity under heat shock conditions.

(A) Quantitation of relative GFP-Lact-C2 levels at the PM in wild type, tcb1/2/3 , and $\Delta$ tether cells at $26^{\circ} \mathrm{C}$ or after $10 \mathrm{~min}$ at $42^{\circ} \mathrm{C}$. Data represents mean \pm standard 
deviation. Total number of cells analysed in three independent experiments: all strains and conditions $n=100 .{ }^{* \star \star *} p>0.0001$; ns, not significant. (B) Quantitation of relative GFP-Lact-C2 levels at the PM in wild type, $t c b 3 \Delta$, and $t c b 3 \Delta$ cells expressing Tcb3GFP, a mutant Tcb3 fusion lacking the SMP domain (Tcb3 $\triangle$ SMP-GFP), or an artificial

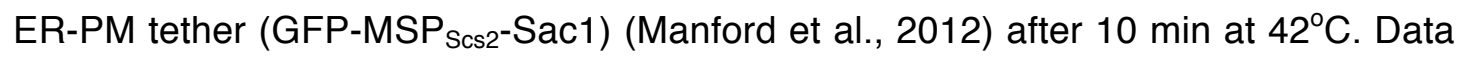
represents mean \pm standard deviation. Total number of cells analysed in three independent experiments: wild type $n=108, \operatorname{tcb} 3 \Delta \mathrm{n}=116, \operatorname{tcb} 3 \Delta+\operatorname{Tcb} 3-\mathrm{GFP} n=108$, $t c b 3 \Delta+$ Tcb3 $\Delta$ SMP-GFP $n=112, t c b 3 \Delta+$ GFP-MSP $\operatorname{Scs}_{2}-$ Sac1 $\left.n=112\right) .{ }^{* * *} p>0.0001$ ns, not significant. (C) PM integrity assays of wild type, tcb3 $\Delta$ and $t c b 3 \Delta$ cells complemented with Tcb3-GFP, Tcb3-GFP truncation mutants (Tcb3 $\Delta$ SMP-GFP or

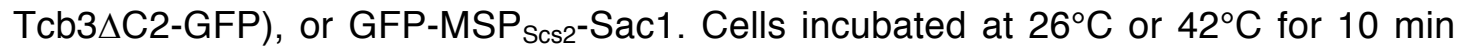
were subsequently incubated with propidium iodide and measured by flow cytometry (50,000 cells measured per experiment). Data represents mean \pm standard deviation from three independent experiments. ${ }^{* * *} p>0.0001$; ns, not significant. Also see Figure S6.

Figure 7. Speculative model for tricalbin protein function in PM phospholipid homeostasis and integrity.

Under normal growth conditions (left panels), non-vesicular phosphatidylserine (PS, magenta) transport from the ER to the PM is carried out by Osh6 and Osh7 that are recruited to ER-PM contacts by Ist2 (D'Ambrosio et al., 2020). Osh6 and Osh7 move PS from the ER to PM in exchange for PI4P (yellow) at the PM (top left, Wild type cells). Under normal growth conditions, the tricalbin (Tcb) proteins may have a structural role in tethering the ER and PM, but they are not required for PS transport as loss of Tcb1/2/3 does not substantially affect PS distribution (bottom left, tcb1/2/3 $\Delta$ cells). 
Under heat shock conditions, however, increases in cytoplasmic $\mathrm{Ca}^{2+}$ levels further induce Tcb3 function. This may include dimerisation with Tcb1/2 and interactions with the PM through the $\mathrm{C} 2$ domains that may promote the ability of the Tcbs to form heatinduced ER-PM contacts (Collado et al., 2019). Importantly, under heat shock conditions, the Tcbs serve a primary role in PS homeostasis at the PM, either by SMP domain-mediated non-vesicular PS transfer from the ER to the PM (top right) or by recruiting additional PS transfer proteins to ER-PM contacts (such as Osh6/7, not depicted). Loss of the Tcb proteins (bottom right, $t c b 1 / 2 / 3 \Delta$ ) leads to a lack of PS delivery to the PM in heat stressed cells, resulting in loss of Pkh1 recruitment (see Figure 5), as well as prolonged $\mathrm{Ca}^{2+}$ bursts and PM integrity defects (bottom right, tcb 1/2/3 $)$. 
bioRxiv preprint doi: https://doi org/10.1101/2021 06.04.447076; this version posted June 4, 2021. The copyright holder for this preprint

(which was not certified by peer review) is the author/funder, who has granted bioRxiv a license to display the preprint in perpetuity. It is made available under aCC-BY-NC-ND 4.0 International license.

\section{Thomas et al., Figure 1}

A

Extracellular

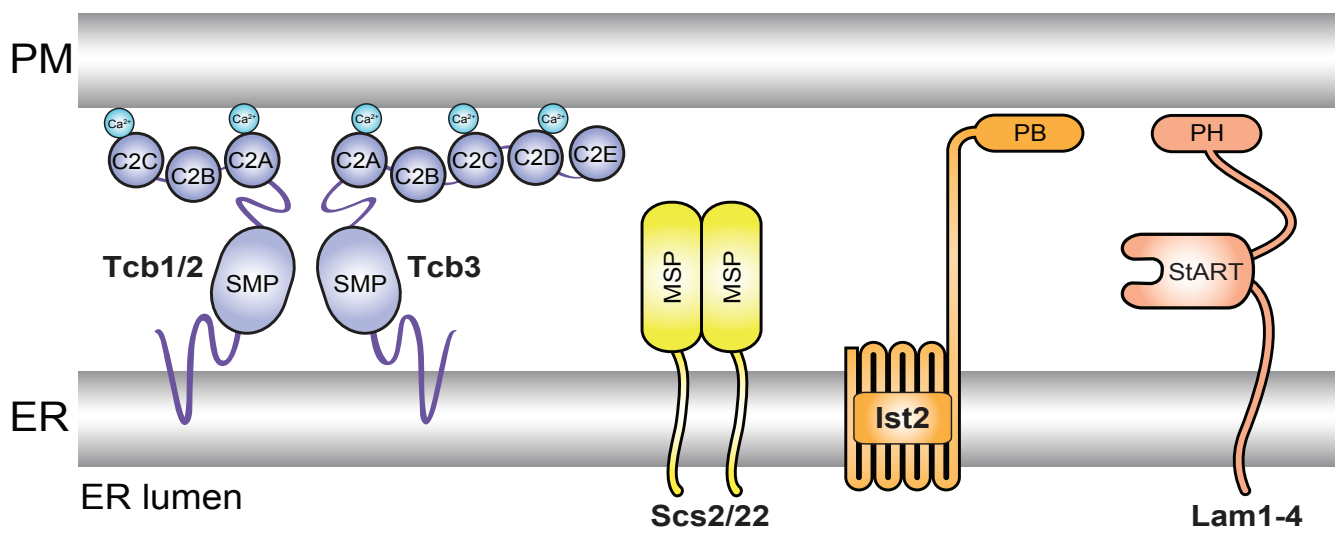

B

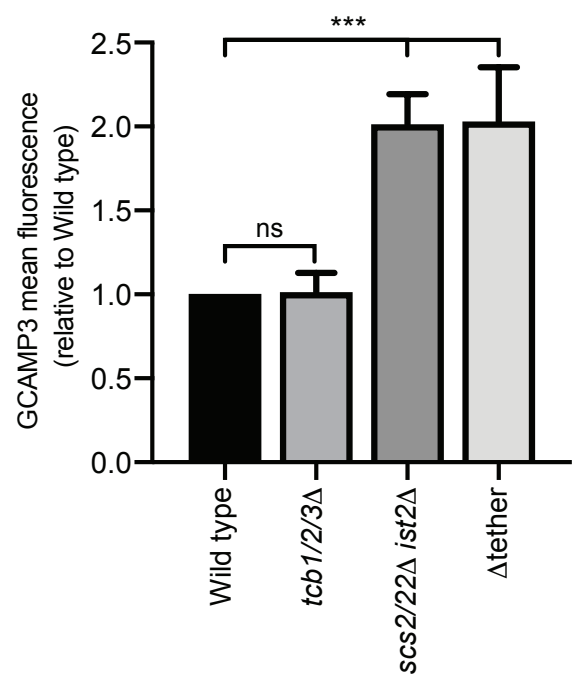

C

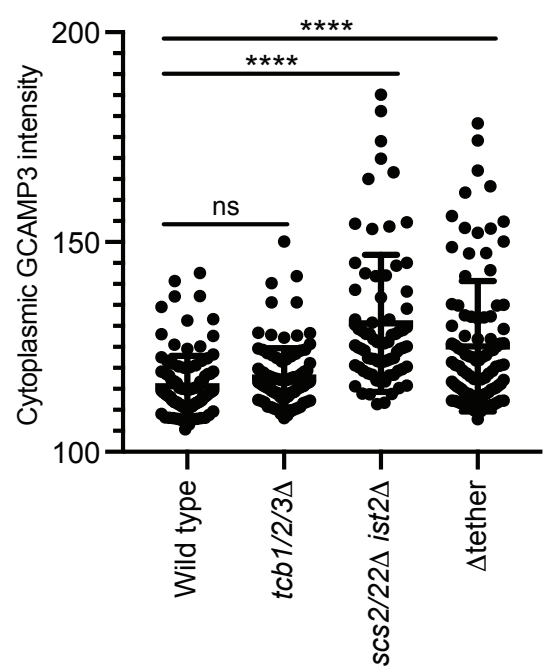




\section{Thomas et al., Figure 2}

A

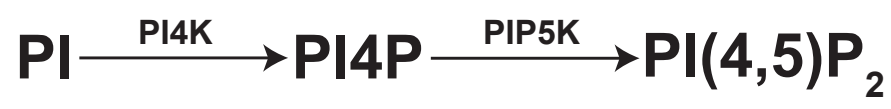

B

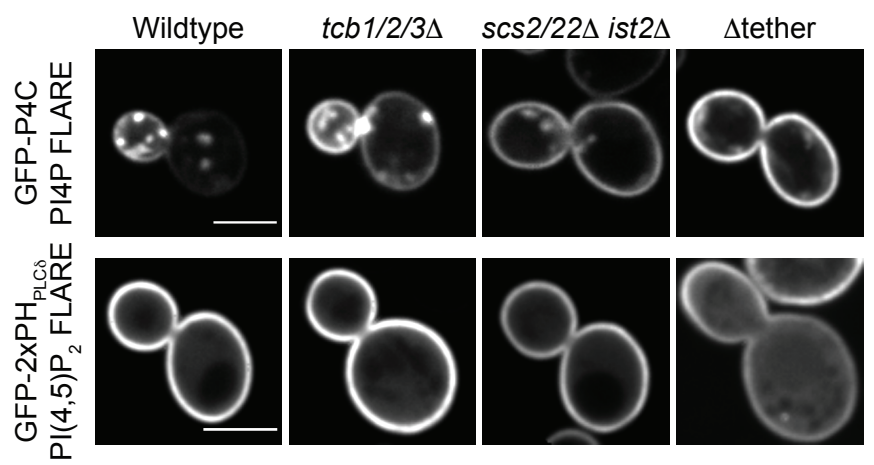

C

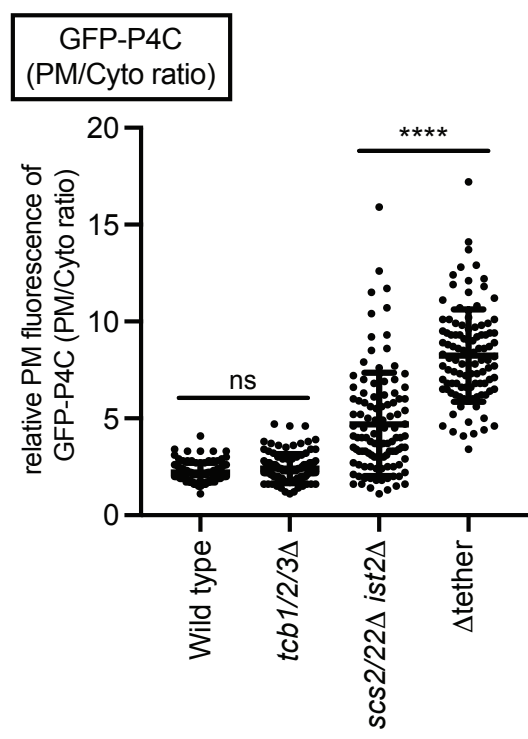

E
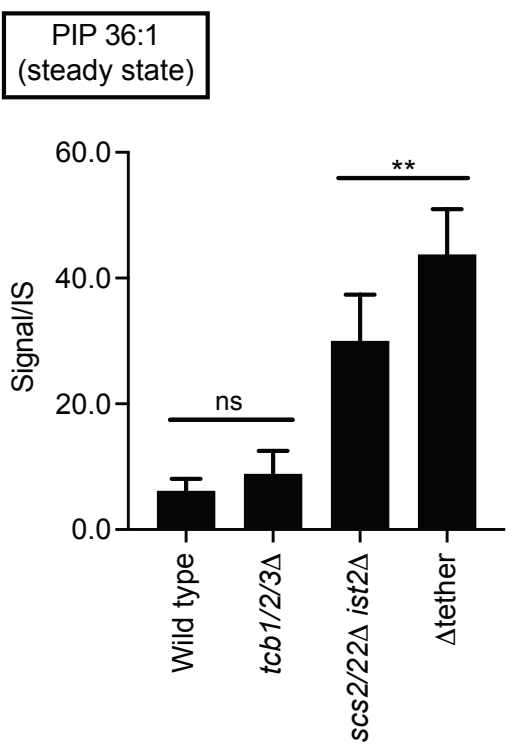

D
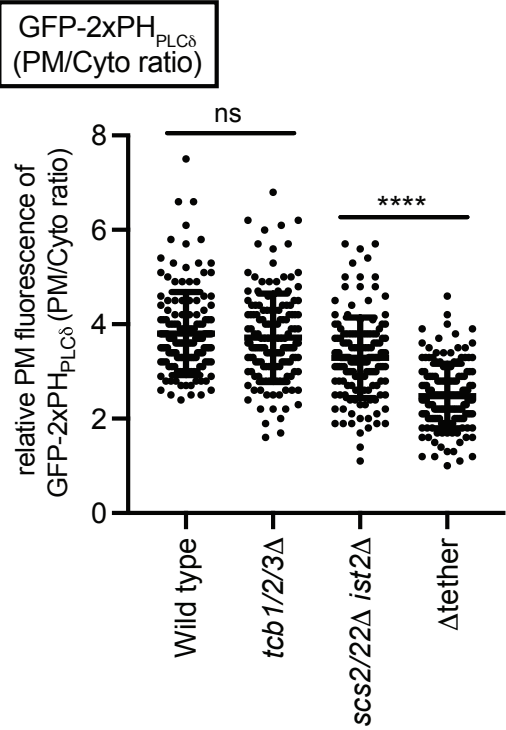

F

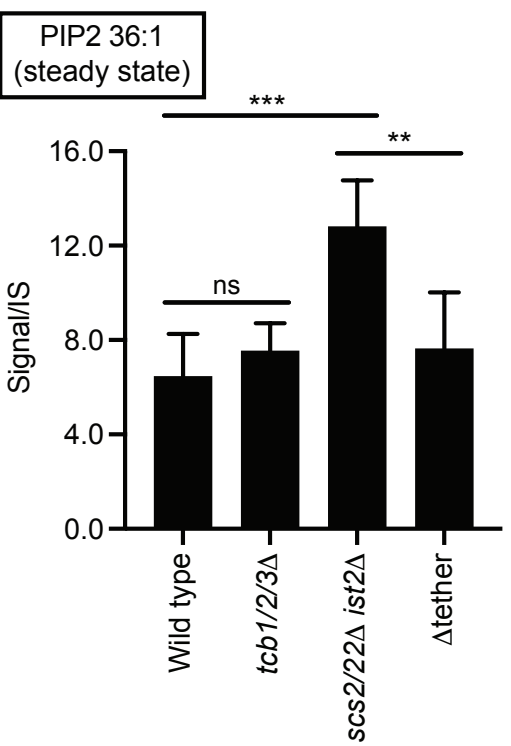




\section{Thomas et al., Figure 3}

A

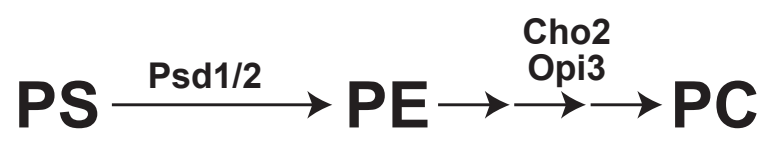

B

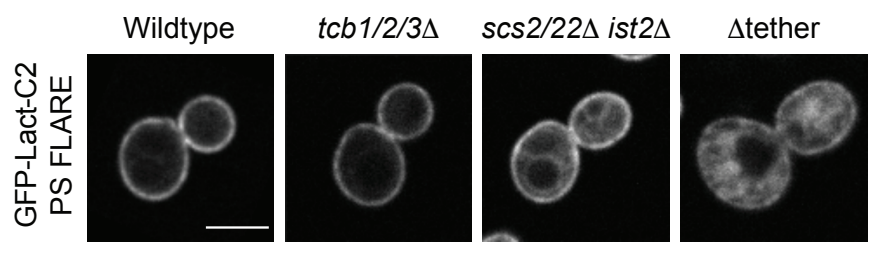

C

GFP-Lact-C2
(PM/cyto ratio)

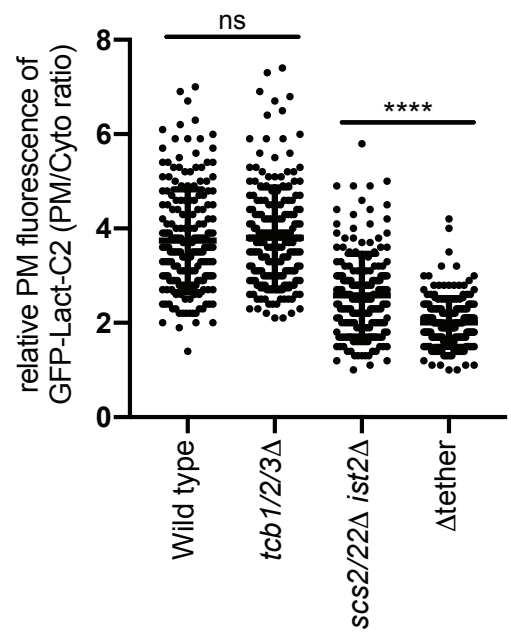

E

PE 34:1
(Steady state)

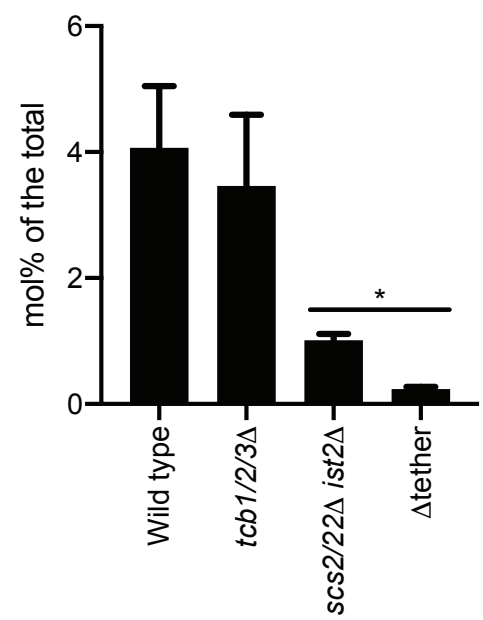

D

PS 34:1
(Steady state)

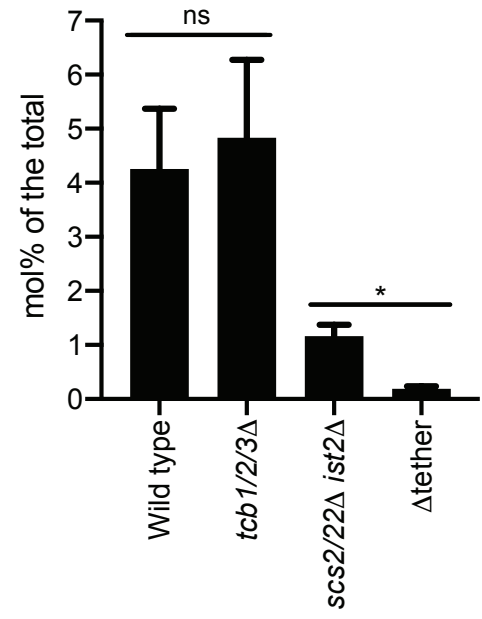

$\mathbf{F}$

PC 34:2

(Steady state)

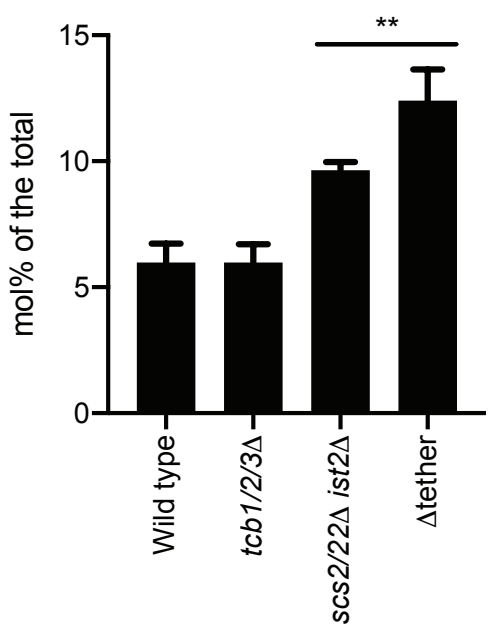


bioRxiv preprint doi: https://doi.org/10.1101/2021.06.04.447076; this version posted June 4, 2021. The copyright holder for this preprin (which was not certified by peer review) is the author/funder, who has granted bioRxiv a license to display the preprint in perpetuity. It is made available under aCC-BY-NC-ND 4.0 International license.

\section{Thomas et al., Figure 4}

A

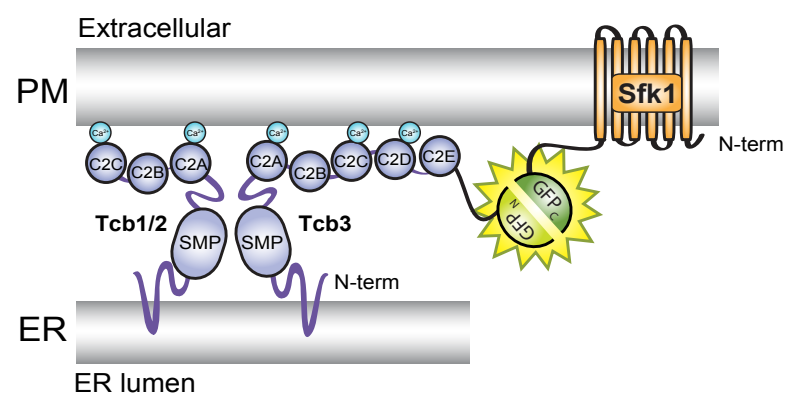

C

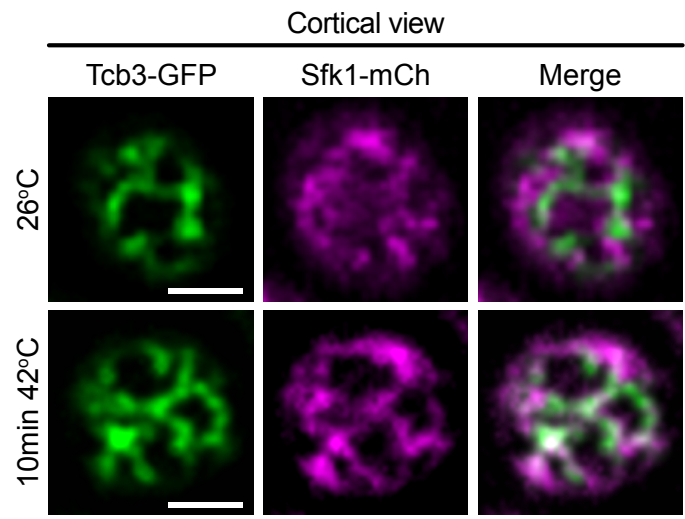

B

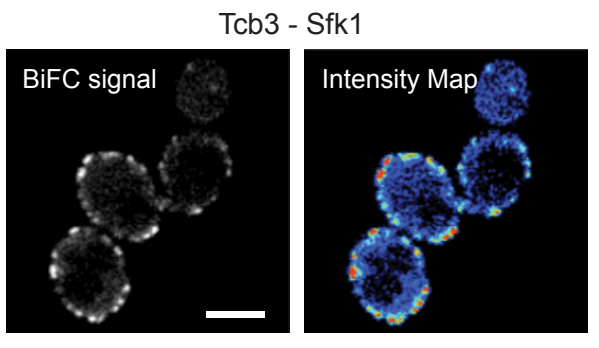

Tcb3 - Sfk1 $1286-353$

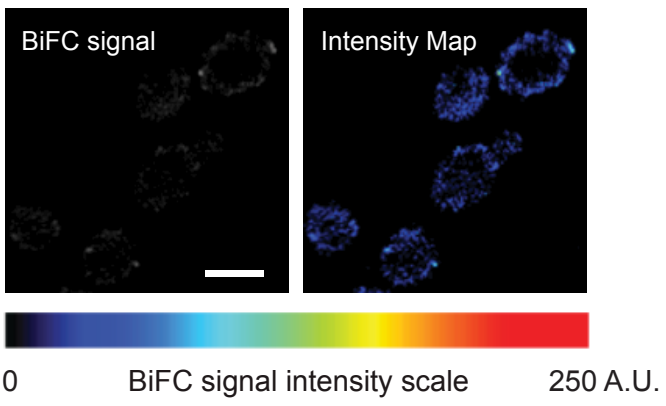

D

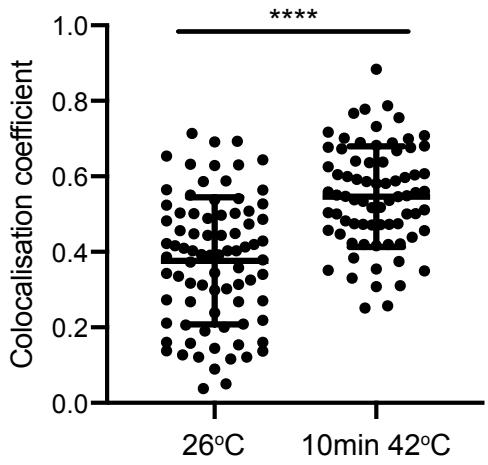


bioRxiv preprint doi: https://doi org/10.1101/2021.06.04.447076: this version posted June 4, 2021. The copyright holder for this preprint (which was not certified by peer review) is the author/funder, who has granted bioRxiv a license to display the preprint in perpetuity. It is made available under aCC-BY-NC-ND 4.0 International license.

\section{Thomas et al., Figure 5}

A

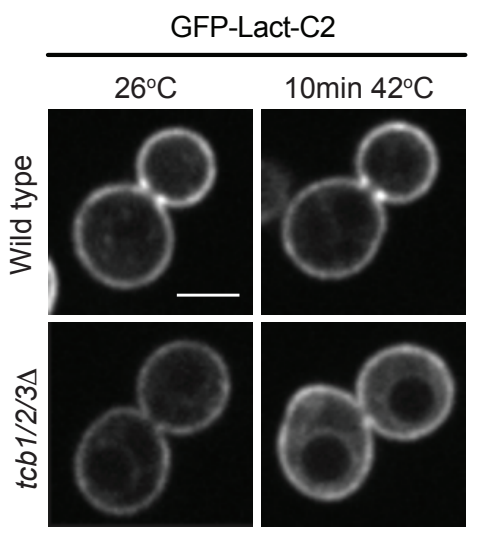

C

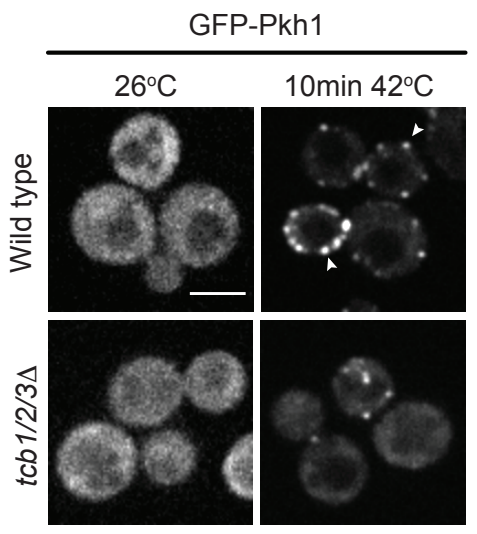

B

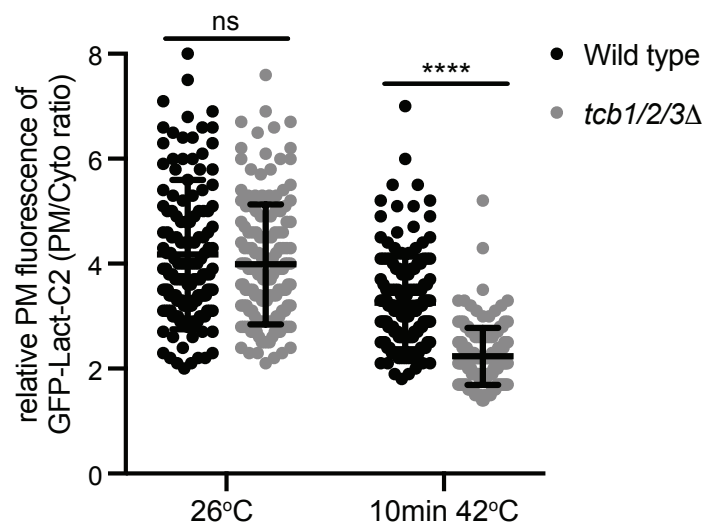

D

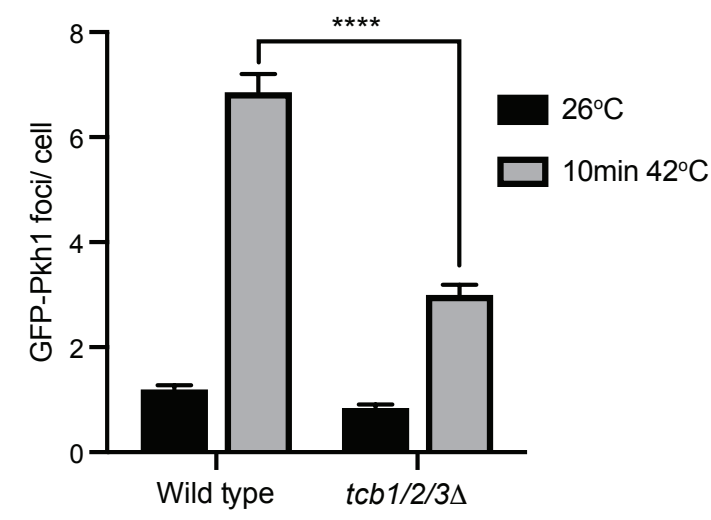




\section{Thomas et al., Figure 6}

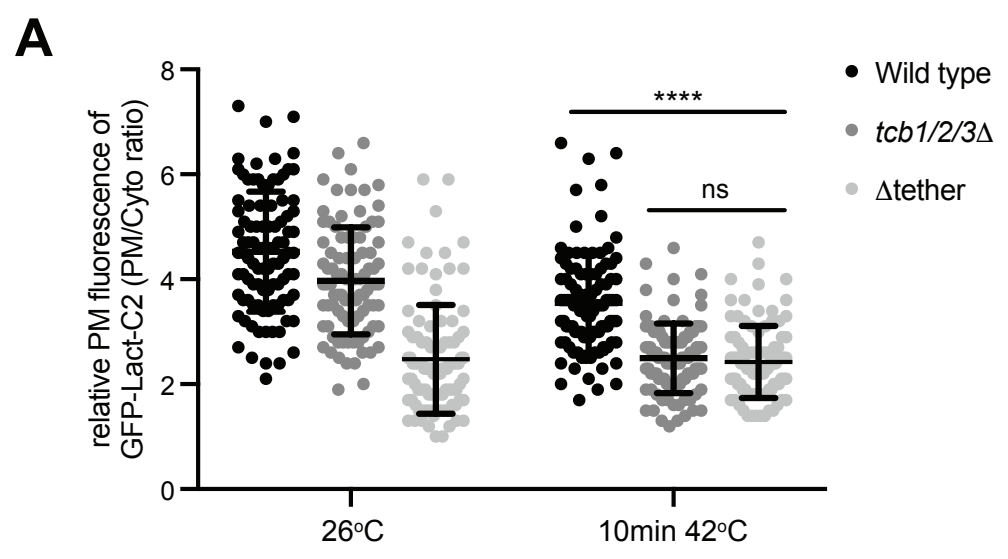

B

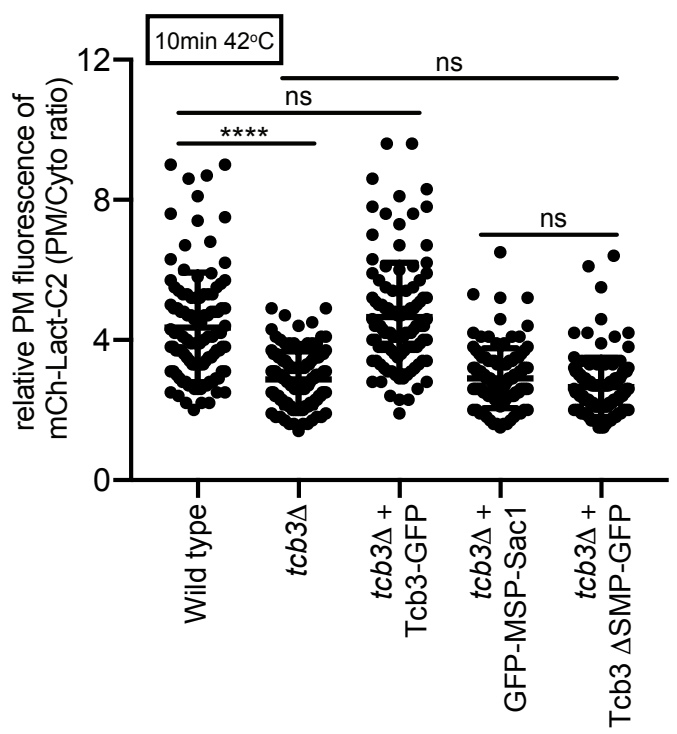

C

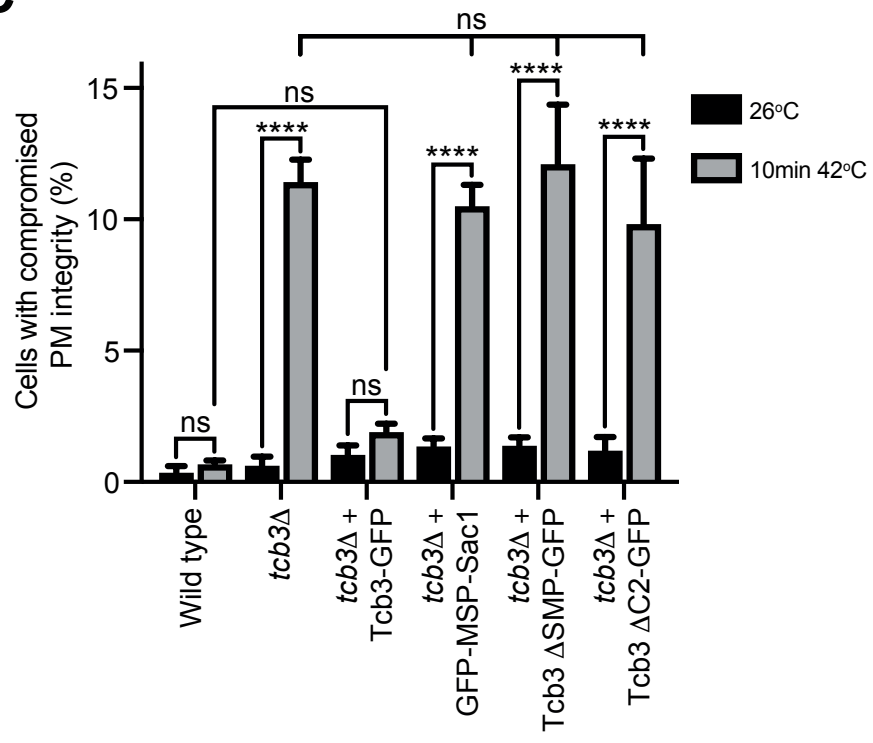


bioRxiv preprint doi: https://doi.org/10.1101/2021.06.04.447076: this version posted June 4, 2021. The copyright holder for this preprint (which was not certified by peer review) is the author/funder, who has granted bioRxiv a license to display the preprint in perpetuity. It is made available under aCC-BY-NC-ND 4.0 International license.

\section{Thomas et al., Figure 7}

Normal growth conditions:

\section{Wild type}

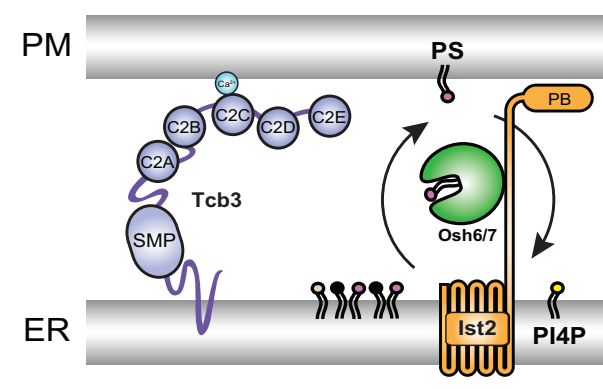

tcb1/2/3 $\Delta$

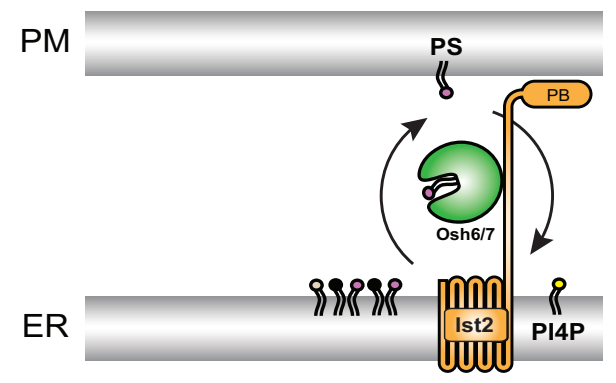

Heat shock conditions:

\section{Wild type}

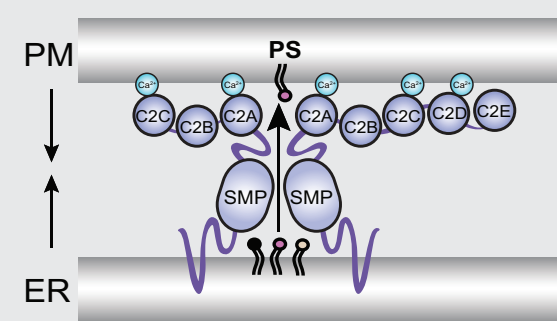

PM phospholipid homeostasis

\section{tcb1/2/3 $\Delta$}
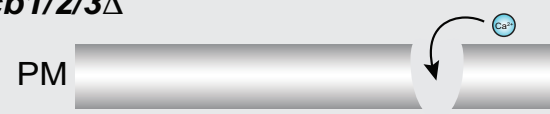

Loss of PM phospholipid homeostasis

Loss of ER-PM lipid flow

ER

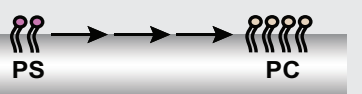

Pkh1 recruitment $\mathrm{Ca}^{2+}$ regulation PM integrity

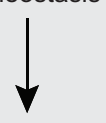

Defects in PM integrity 


\section{Additional Data Files}

\section{Supplemental Figure Legends}

Figure S1. Deletion of the stretch- activated $\mathrm{Ca}^{2+}$ channel Mid1 in $\operatorname{scs} 2 / 22 \Delta$ ist2 $\Delta$ cells phenocopies the $\Delta$ tether mutant cells.

(A) Serial dilutions (10-fold) of wild type, mid $1 \Delta, \operatorname{scs} 2 / 22 \Delta$ ist2 $\Delta, \operatorname{scs} 2 / 22 \Delta$ ist2 $\Delta$ mid1 $\Delta$ and $\Delta$ tether cells spotted on agar media $+/-0.75 \mu \mathrm{M}$ myriocin. (B) Quantitation of the PS FLARE (GFP-Lact-C2) intensity at the PM of wild type, scs2/22 $\Delta$ ist2 $\Delta, \Delta$ tether, and $\operatorname{scs} 2 / 22 \Delta$ ist 2 mid1 $1 \Delta$ cells. Data represents mean \pm standard deviation. Total number of cells analysed in three independent experiments: wild type $n=172, \operatorname{scs} 2 / 22 \Delta$ ist2 $\Delta \mathrm{n}=178, \Delta$ tether $\mathrm{n}=177, \operatorname{scs} 2 / 22 \Delta$ ist2 $\Delta$ mid1 $\Delta \mathrm{n}=181 .{ }^{* * *} \mathrm{p}>0.0001$.

Figure S2. Lipidomic analyses of individual phosphoinositide species in the various ER-PM tether mutants.

(A) Schematic representation of $\mathrm{PI} 4 \mathrm{P}$ and $\mathrm{PI}(4,5)_{2}$ production from $\mathrm{PI}$ and the kinases involved. (B) Levels of PI, PIP, and $\mathrm{PIP}_{2}$ species in wild type, $t c b 1 / 2 / 3 \Delta, s c s 2 / 22 \Delta$ ist2 $\Delta$, and $\Delta$ tether cells. Data represents mean \pm standard deviation $(N=5) .{ }^{*} p>0.1,{ }^{* *} p>$ 0.01 .

Figure S3. Lipidomic analyses of individual PS, PE, and PC species in the various ER-PM tether mutant strains.

(A) Schematic representation of PE and PC production from PS and the enzymes involved. (B) Levels of PS, PE, and PC species in wild type, tcb1/2/3 $\Delta$, scs2/22 $\Delta$ ist2 $\Delta$, and $\Delta$ tether cells. Data represents mean \pm standard deviation $(\mathrm{N}=3) .{ }^{*} \mathrm{p}>0.1,{ }^{\star *} \mathrm{p}>$ 0.01 . 
Figure S3. Tcb3 and Sfk1 display specifically associate, and heat stress results in cytoplasmic $\mathrm{Ca}^{2+}$ bursts.

(A) Control protein-protein proximity assays; Protein-protein interactions between Tcb3 or Tcb3 ${ }^{\triangle 478-1545}$ alone (top) or ER- localized Sec61 and either Tcb3 or Sfk1 (bottom) as detected by the split GFP BiFC assay. In each case, GFP is fused to the protein listed on the left and GFP $\mathrm{C}_{\mathrm{C}}$ is fused to the protein on listed on the right. (B) Normalised GCaMP3 fluorescence $\left(\Delta \mathrm{F} / \mathrm{F}_{0}\right)$ traces of wild type cells incubated the indicated temperature. Each line represents an individual cell, 49 (top) and 48 (bottom) traces for each condition. (C) Mean maximum normalised fluorescence $\left(\Delta F / F_{0}\right)$ in wild type cells incubated at the indicated temperatures. Data represents mean \pm standard deviation. Total number of cells analysed in three independent experiments: wild type $26^{\circ} \mathrm{C}, \mathrm{n}=150$; wild type $10 \min 42^{\circ} \mathrm{C}, \mathrm{n}=151{ }^{* \star * \star} \mathrm{p}>0.0001$. (D) Quantitation of the percentage of cells undergoing a calcium burst within 5 minutes after incubation at the temperature indicated. Data represents mean \pm standard deviation in three independent experiments ( $n=50$ cells per experiment). ${ }^{* * *} p>0.0001$.

\section{Figure S5. Heat-induced Pkh1 cortical puncta are regulated by Sfk1 and PM phospholipid asymmetry.}

(A) DAG FLARE (GFP-C $1_{\text {PKD1 }}$ ) localisation in wild type and $t c b 1 / 2 / 3 \Delta$ cells at $26^{\circ} \mathrm{C}$ or after a brief heat shock $\left(10 \min 42^{\circ} \mathrm{C}\right)$. Scale bar, $4 \mu \mathrm{m}$. (B) Schematic representation of GFP-Pkh1. (C) Quantitation of the number of GFP-Pkh1 puncta per cell in wild type and $s f k 11 \Delta$ cells at the indicated temperatures. Total number of cells analysed in three independent experiments: all strains and conditions, $n=300)$. ${ }^{* * * *} p>0.0001$. (D) Quantitation of the number of GFP-Pkh1 foci per cell in wild type, dnf1/2/3L, and $\operatorname{prd} 5 \Delta$ snq2 $\Delta$ yor $1 \Delta$ cells at the indicated temperatures. Total number of cells analysed in three independent experiments: all strains and conditions $n=400$. ${ }^{* * *} p>0.0001$. 
Figure S6. Tricalbin proteins regulate cytosolic $\mathrm{Ca}^{2+}$ burst intensity under heat stress conditions.

(A) Normalised specific GCaMP3 fluorescence $\left(\Delta F / F_{0}\right)$ traces of wild type and tcb 1/2/3 $\Delta$ cells incubated at $42^{\circ} \mathrm{C}$ for $10 \mathrm{~min}$. Each line represents an individual cell, 62 (top) and 59 (bottom) traces for each condition. (B and C) Mean maximum normalized specific fluorescence $\left(\Delta \mathrm{F} / \mathrm{F}_{0}\right)(\mathbf{B})$ and duration of calcium bursts $(\mathbf{C})$ in wild type and $t c b 1 / 2 / 3 \Delta$ cells 5 minutes after incubation at the temperature indicated. Data represents mean \pm standard deviation. Total number of cells analysed in three independent experiments: wild type $10 \min 42^{\circ} \mathrm{C} n=150, t c b 1 / 2 / 3 \Delta 10 \min 42^{\circ} \mathrm{C}$ $n=148) .{ }^{* \star * *} p>0.0001$. 
bioRxiv preprint doi: https://doi.org/10.1101/2021.06.04.447076; this version posted June 4, 2021. The copyright holder for this preprint (which was not certified by peer review) is the author/funder, who has granted bioRxiv a license to display the preprint in perpetuity. It is made available under aCC-BY-NC-ND 4.0 International license.

\section{Thomas et al., Figure S1}

A

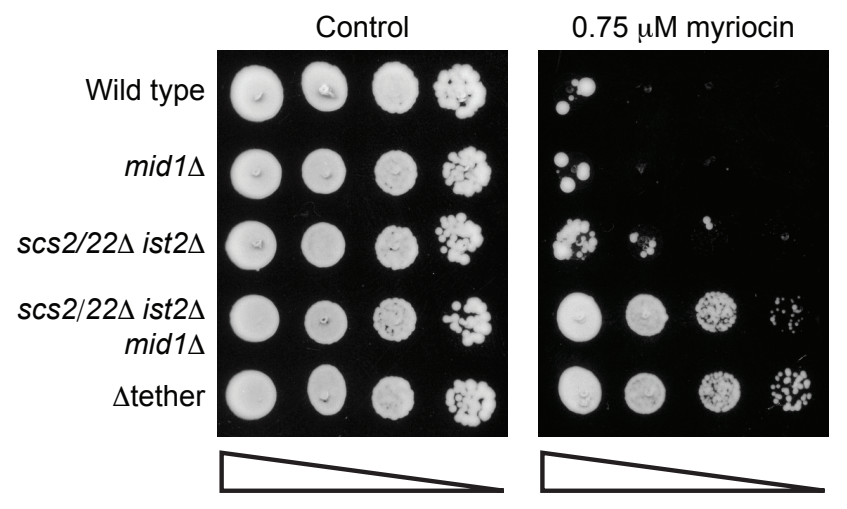

B

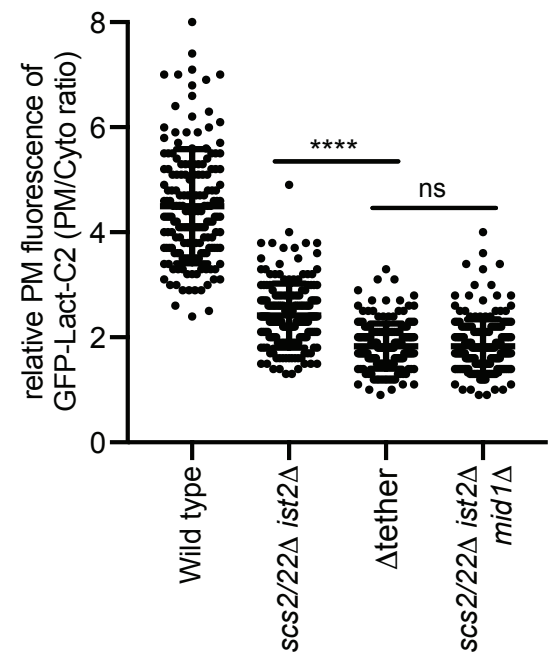




\section{Thomas et al., Figure S2}

A

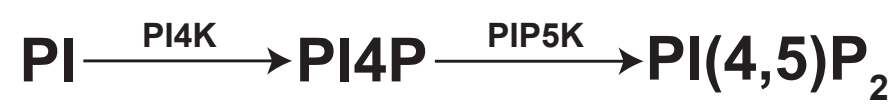

B
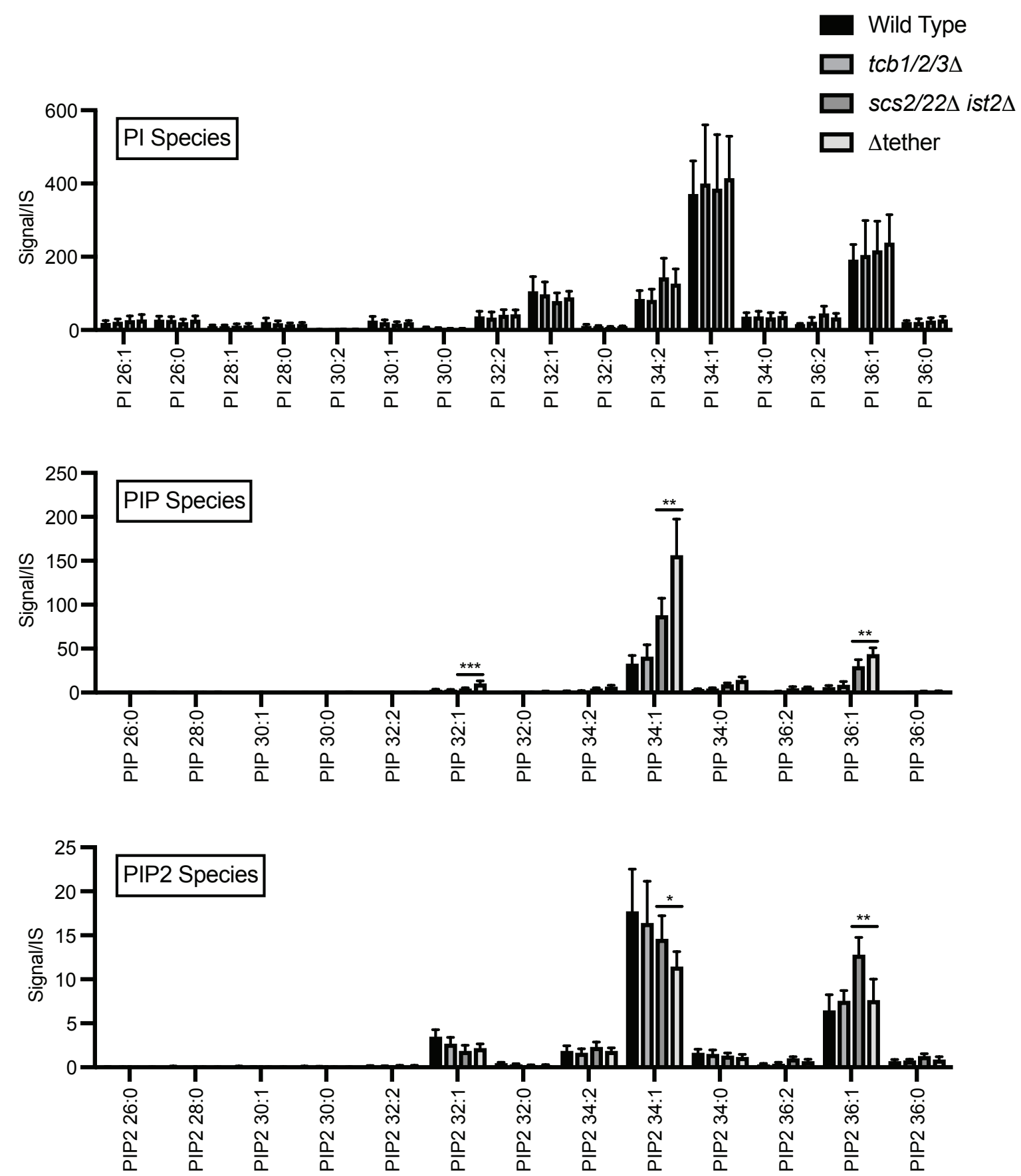


\section{Thomas et al., Figure S3}

A

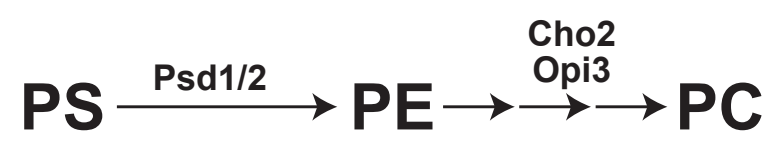

B
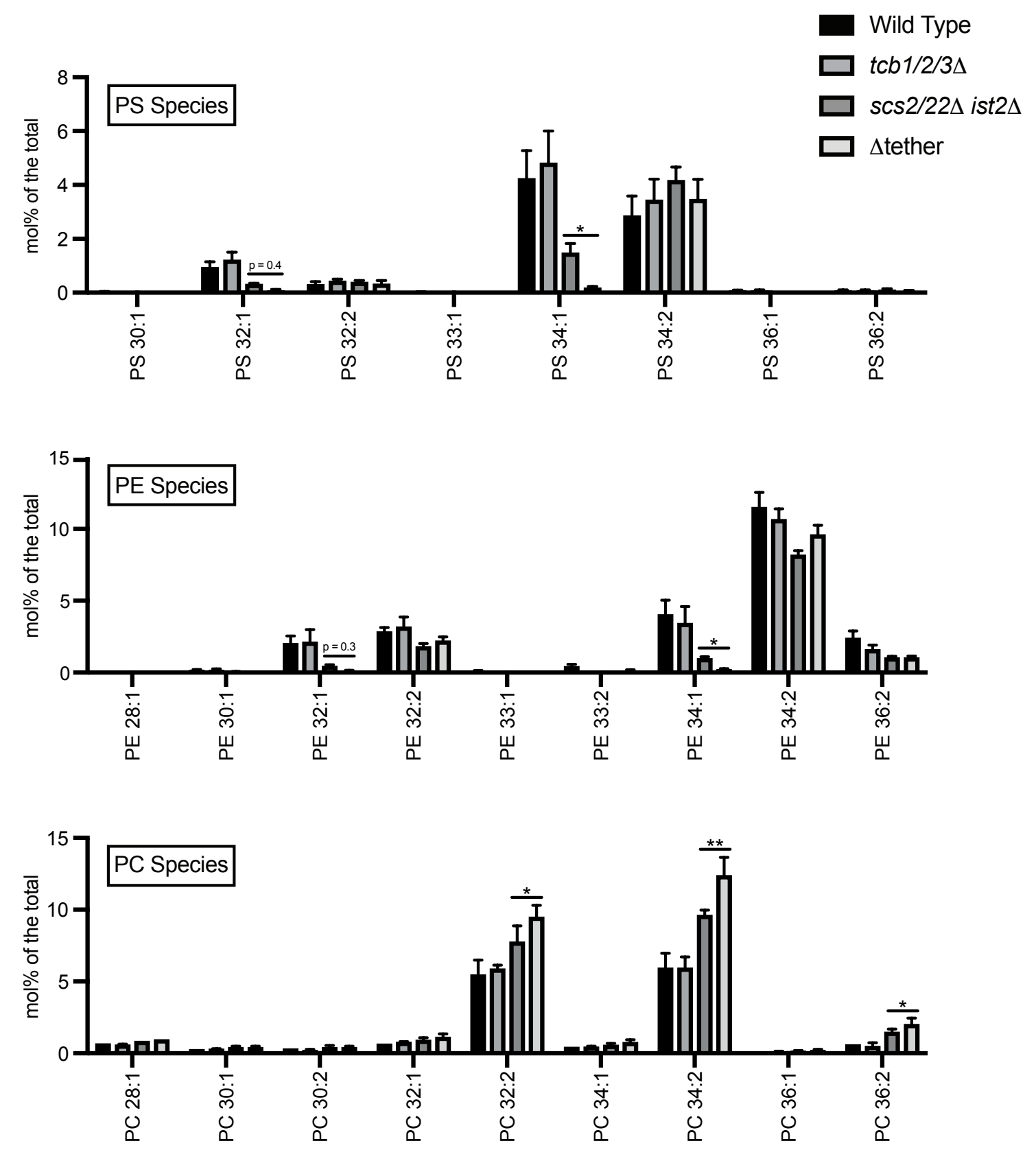
bioRxiv preprint doi: https://doi.org/10.1101/2021.06.04.447076: this version posted June 4 2021. The copvriaht holder for this preprint

\section{Thomas et al., Figure S4}

A

Tcb3 - Tcb3

$\operatorname{Tcb}^{\triangle 478-1545}-\mathrm{Tcb}^{\Delta 478-1545}$
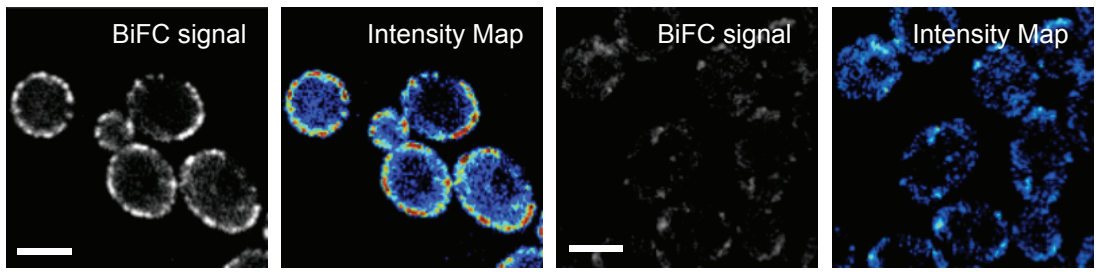

Sec61 - Sfk1

Sec61 - Tcb3
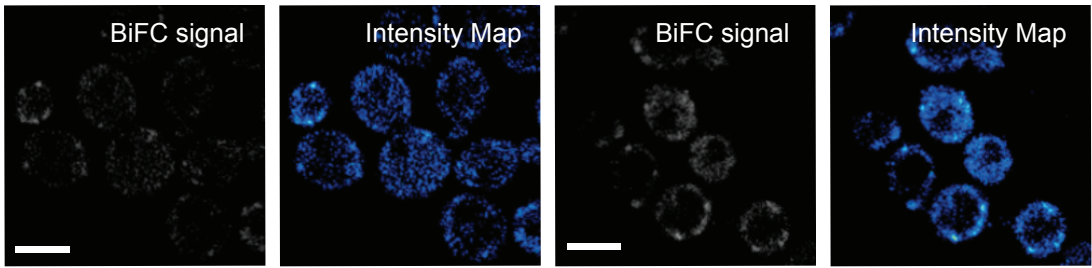

0

BiFC signal intensity scale

250 A.U.

B
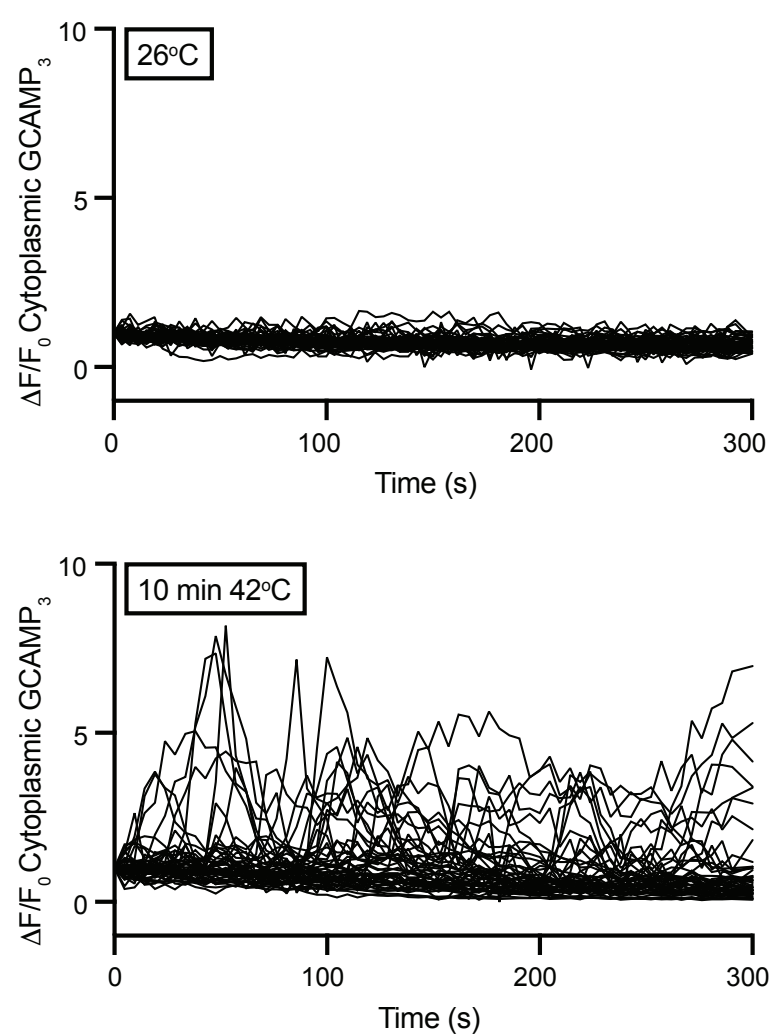

C
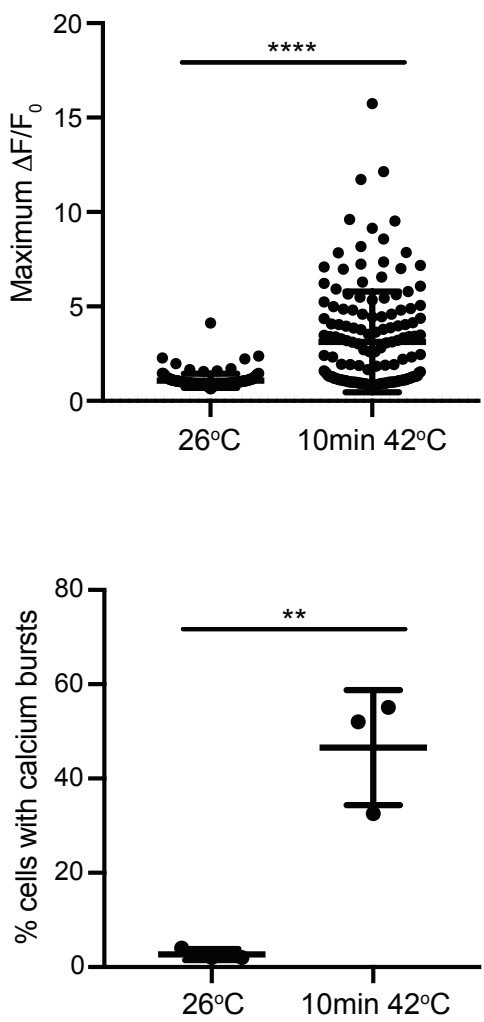
bioRxiv preprint doi: https://doi org/10.1101/2021.06.04.447076: this version posted June 4, 2021. The copyright holder for this preprint (which was not certified by peer review) is the author/funder, who has granted bioRxiv a license to display the preprint in perpetuity. It is made available under aCC-BY-NC-ND 4.0 International license.

\section{Thomas et al., Figure S5}

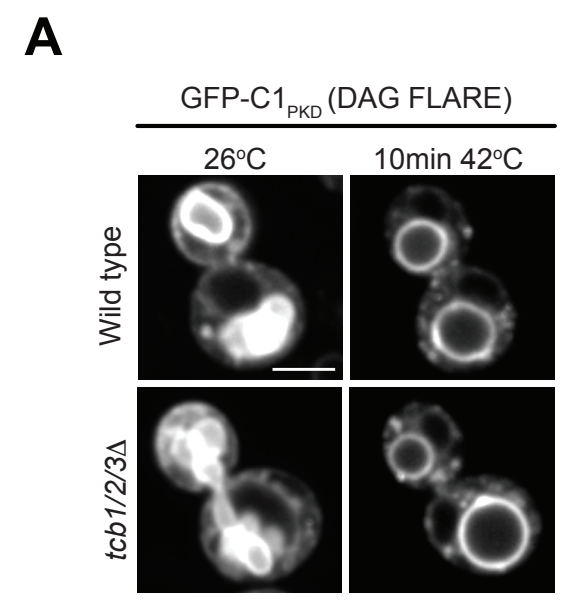

B

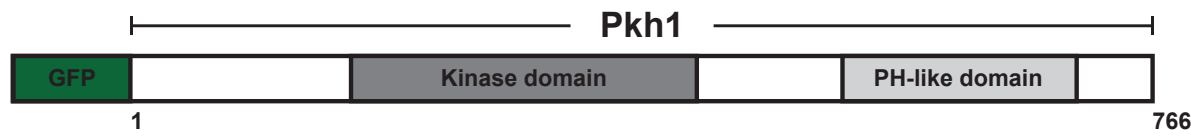

C

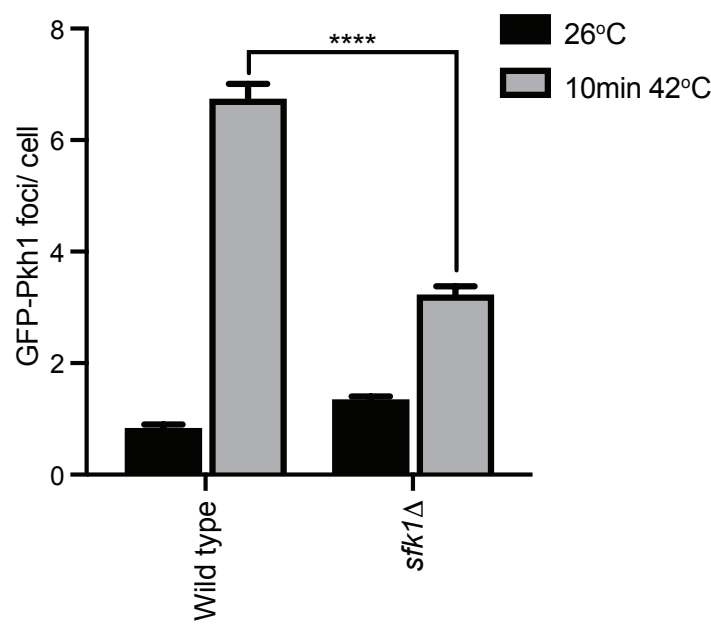

D

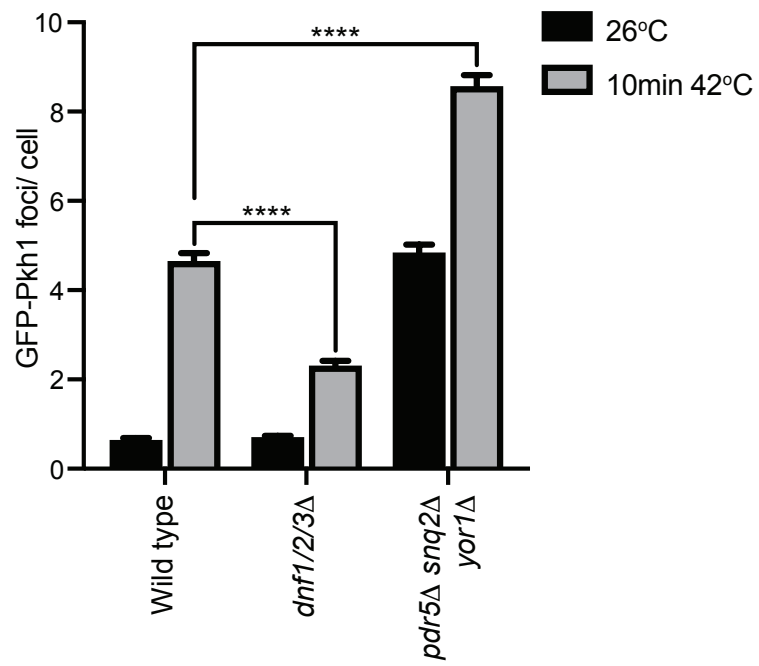


bioRxiv preprint doi: https://doi.org/10.1101/2021.06.04.447076: this version posted June 4 2021. The copyriaht holder for this preprint

Thomas et al., Figure S6

A
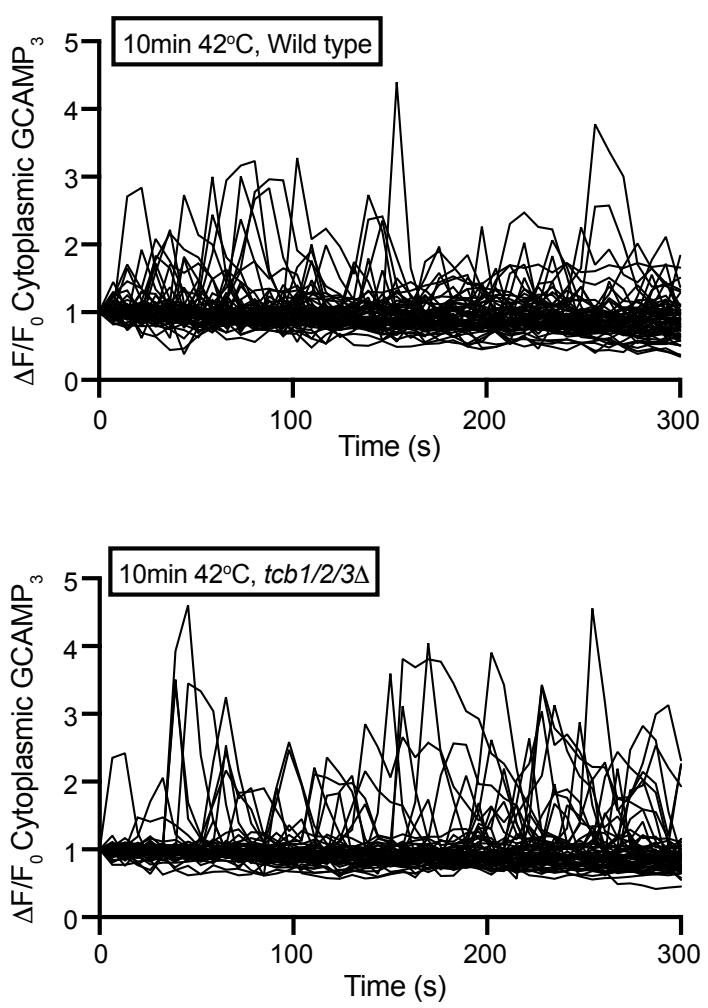

B

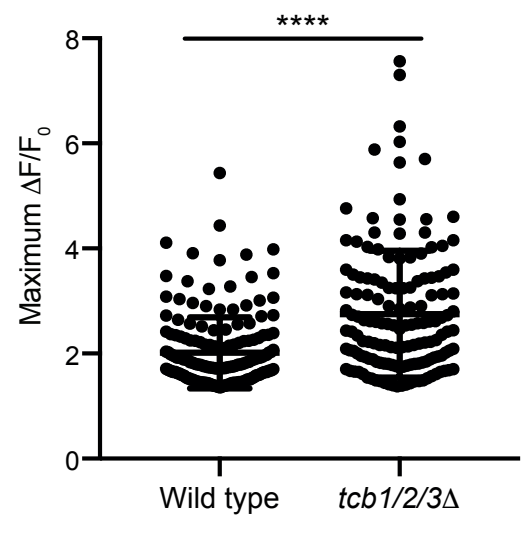

C

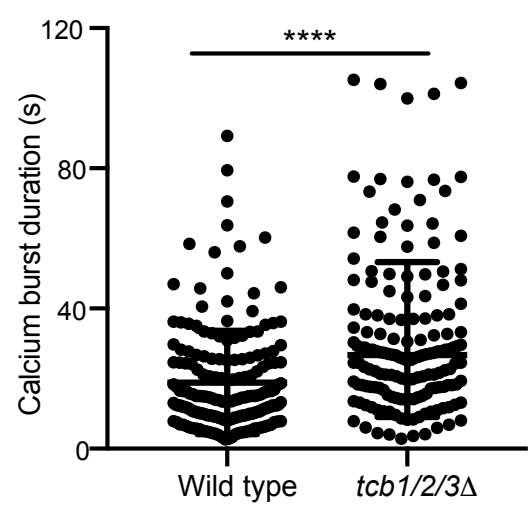




\section{Supplemental Tables}

\begin{tabular}{|c|c|c|}
\hline \multicolumn{3}{|c|}{ Supplemental Table 1. Saccharomyces cerevisiae strains used in this study. } \\
\hline Strain & Genotype & Reference/Source \\
\hline SEY6210 & $\begin{array}{l}\text { MATa leu2-3,112 ura3-52 his3 } \Delta 200 \text { trp1- } \\
\Delta 901 \text { lys2-801 suc2 } 99\end{array}$ & (Robinson et al., 1988) \\
\hline SEY6210.1 & $\begin{array}{l}\text { MATa leu2-3, } 112 \text { ura3-52 his3 } \Delta 200 \text { trp1- } \\
\Delta 901 \text { lys2-801 suc2 } \Delta 9\end{array}$ & (Robinson et al., 1988) \\
\hline ANDY214 & 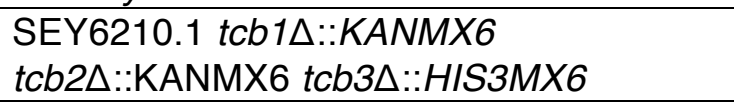 & (Manford et al., 2012) \\
\hline ANDY129 & $\begin{array}{l}\text { SEY6210.1 ist2 }::: H I S 3 M X 6 \text { scs2 } \triangle:: T R P 1 \\
\text { scs22 } \triangle:: H I S 3 M X 6\end{array}$ & (Manford et al., 2012) \\
\hline ANDY198 & $\begin{array}{l}\text { SEY6210.1 ist2 }::: H I S 3 M X 6 \text { scs2 } \triangle:: T R P 1 \\
\text { scs22 } \triangle:: H I S 3 M X 6 \text { tcb1 } 1:: \text { KANMX6 } \\
\text { tcb2 }:: \text { KANMX6 tcb3 } \triangle:: H I S 3 M X 6\end{array}$ & (Manford et al., 2012) \\
\hline YCS648 & SEY6210.1 mid1::HIS3MX6 & This study \\
\hline YCS652 & $\begin{array}{l}\text { SEY6210.1 ist2::HIS3MX6 scs2::TRP1 } \\
\text { scs22::HIS3MX6 mid1::HIS3MX6 }\end{array}$ & This study \\
\hline HYY1 & SEY6210 TCB3-GFP $:: H I S 3 M X 6$ & Scott Emr lab \\
\hline HYY2 & SEY6210.1 TCB3-GFP ${ }_{\mathrm{N}}:$ TRP1 & Scott Emr lab \\
\hline YCS2211 & SEY6210.1 tcb3 ${ }^{\Delta 478-1545}-G_{F P}:: T R P 1$ & This study \\
\hline YCS2216 & SEY6210 tcb3 $3^{\Delta 478-1545}-$ GFP $_{C}:: H I S 3 M X 6$ & This study \\
\hline HYY3 & SEY6210 SFK1-GFP $:: H I S 3 M X$ & Scott Emr lab \\
\hline YCS2218 & SEY6210 sfk $1^{\Delta 286-353}-$ GFP $_{\mathrm{C}}:: H I S 3 M X 6$ & This study \\
\hline YCS2207 & SEY6210.1 SEC61-GFP $:: T R P 1$ & This study \\
\hline FTY1 & $\begin{array}{l}\text { SEY6210.1 TCB3-GFP::TRP1 } \\
\text { SFK1-mCherry::HIS3MX6 }\end{array}$ & This study \\
\hline BY4741 & MATa his3 $\Delta 1$ leu2 $\Delta 0$ met $15 \Delta 0$ ura3 $\Delta 0$ & $\begin{array}{l}\text { (Brachmann et al., } \\
\text { 1998) }\end{array}$ \\
\hline PFY3272C & $\begin{array}{l}\text { BY4741 dnf1::KANMX6 dnf2::KANMX6 } \\
\text { dnf3::KANMX6 }\end{array}$ & (Hua et al., 2002) \\
\hline & $\begin{array}{l}\text { BY4741 pdr5::KANMX6 snq2::KANMX6 } \\
\text { yor1::KANMX6 }\end{array}$ & Jeremy Thorner lab \\
\hline
\end{tabular}




\begin{tabular}{|c|c|c|}
\hline \multicolumn{3}{|c|}{ Supplemental Table 2. Plasmids used in this study. } \\
\hline $\begin{array}{l}\text { Plasmid } \\
\text { Name }\end{array}$ & Description & Reference/Source \\
\hline & pRS416-pGPD-GFP-P4C SidC $_{1}$ & (Luo et al., 2015) \\
\hline pCS189 & pRS426-pPRC1-GFP-2xPH ${ }_{\text {PLC }}$ & (Stefan et al., 2002) \\
\hline \multirow[t]{3}{*}{ pCS468 } & pRS415-pGPD-GCaMP3 & (Omnus et al., 2016) \\
\hline & pRS416-pGPD-GFP-Lact-C2 & (Fairn et al., 2011) \\
\hline & pRS416-pGPD-mCherry-Lact-C2 & (Fairn et al., 2011) \\
\hline pCS174 & pRS426-GFP-C $1_{\mathrm{PKD}}$ & This study \\
\hline pCS459 & pRS416-pPKH1-GFP-PKH1 & (Omnus et al., 2016) \\
\hline pAM43 & pRS415-pTCB3-TCB3-GFP-tADH1 & (Manford et al., 2012) \\
\hline pAM44 & pRS415-pTCB3-tcb3 ${ }^{\triangle 478-1545}$-GFP-t $A D H 1$ & (Manford et al., 2012) \\
\hline pCB2 & pRS415-pTCB3-tcb3 ${ }^{\triangle S M P}-G F P-t A D H 1$ & (Collado et al., 2019) \\
\hline pAM38 & pRS415-pADH1-GFP-MSP ${ }_{\mathrm{Scs} 2}-S A C 1$ & (Manford et al., 2012) \\
\hline
\end{tabular}

